\title{
Seismic Collapse Analysis of RC Highway Bridges Based on a Simplified Multiscale FE Modeling Approach
}

\author{
Menghan Hu, ${ }^{1}$ Qiang Han, ${ }^{1}$ Xiuli Du, ${ }^{1}$ and Xiao Liang ${ }^{2}$ \\ ${ }^{1}$ Key Laboratory of Urban Security and Disaster Engineering of Ministry of Education, Beijing University of Technology, \\ Beijing 100124, China \\ ${ }^{2}$ Tianjin Key Laboratory of Civil Structure Protection and Reinforcement, Tianjin Chengjian University, Tianjin 300384, China
}

Correspondence should be addressed to Qiang Han; qhan@bjut.edu.cn

Received 24 August 2017; Accepted 6 November 2017; Published 23 November 2017

Academic Editor: Evgeny Petrov

Copyright (C) 2017 Menghan Hu et al. This is an open access article distributed under the Creative Commons Attribution License, which permits unrestricted use, distribution, and reproduction in any medium, provided the original work is properly cited.

\begin{abstract}
Multiscale finite element (FE) modeling offers a balance between computational efficiency and accuracy in numerical simulations, which is appropriate for analysis of seismic collapse of RC highway bridges. Some parts of structures that need detailed analysis can be modeled by solid elements, while some subordinate parts can be simulated by beam elements or shell elements to increase the computational efficiency. In the present study, rigid surface coupling method was developed to couple beam elements with solid elements using the LS-DYNA software. The effectiveness of this method was verified by performing simulation experiments of both a single-column pier and a two-span simply supported beam bridge. Using simplified multiscale FE modeling, analyses of collapse and local failure of a multispan simply supported beam bridge and a continuous rigid frame bridge were conducted to illustrate the approach in this paper. The results demonstrate that the simplified multiscale model reasonably simulates the collapse process and local damage of complex bridges under seismic loading.
\end{abstract}

\section{Introduction}

Highway bridges were severely damaged or collapsed during past strong earthquakes, which brought many difficulties to rehabilitation [1]. Figure 1 shows the unseating failure of bridge spans during the 2008 Wenchuan earthquake with a magnitude of $\mathrm{ML}=8.0$ [2]. Therefore, the failure prediction of bridges, damage mitigation, and unseating prevention at expansion joints of multispan bridges are important issues of seismic design for highway bridges. There are three methods used for simulating the earthquake-induced failures of bridges: Discrete Element Method (DEM), Applied Element Method (AEM), and Finite Element Method (FEM). Currently, FEM is one of the most commonly used methods of simulating the collapse process of bridges [3-5]. A detailed 3D FE model elaborately simulated the damage location and the local failure mechanism of highway bridges [6-8]. Although detailed 3D FE model provides good precision, the cost of computation is high. It is necessary to develop an appropriate method that not only accurately reflects the damage process but also improves the computational efficiency. To satisfy the demands of engineering practice, multiscale FE modeling uses different types of elements to simulate different parts of structures, which is an effective method to balance precision and efficiency [9].

In the past years, many researchers have applied multiscale FE modeling approach to study the failure mechanism of frame structures. Bin and Li [10] developed a suited concurrent multiscale approach to simulate the trans-scale failure of large concrete structures and performed tests to compare experimental observations with numerical analysis results. Tao and Nie [11] proposed a multiscale modeling method for evaluating the deformation mechanism of composite joint substructures in a CFST (concrete filled steel tubular) column-composite floor frame structural system. Margiacchi et al. [12] simulated the nonlinear static response of an infilled moment-resisting steel frame by using a multiscale FE model. It is important to study the coupling modes for realizing the incorporation of different dimensional elements in multiscale numerical model. McCune et al. [13] proposed a method that can correctly couple beam elements to shell 


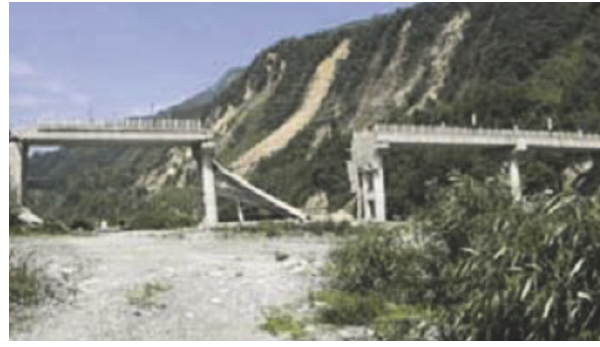

(a) Gaoyuan bridge

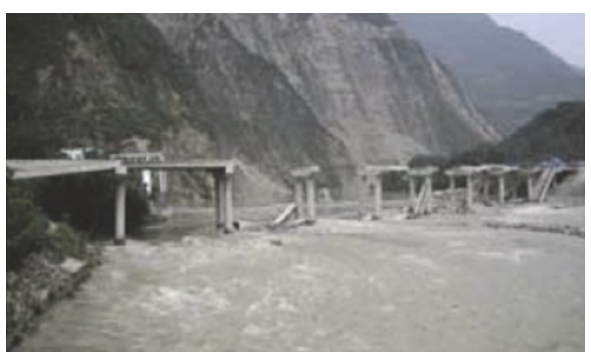

(b) Nanba bridge

FIGURE 1: The failure of bridges under earthquake.

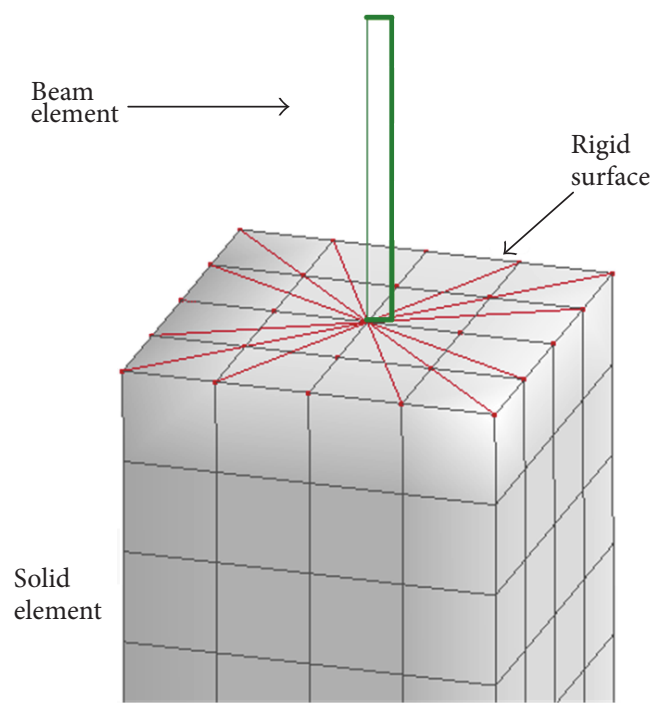

FIGURE 2: Model of coupling surface.

elements and shell elements to solid elements, and Shim et al. [14] provided a novel relationship among nodal degrees of freedom between the different dimensional element types in elastic regions. In addition, the multiscale numerical simulation was also applied to bridge engineering to analyze the damage process of bridges [15-17]. Wang [18] investigated the failure of a multispan simply supported girder bridge subjected to pounding and sliding under severe ground motion by numerical simulation. Chan et al. [19] studied the nonlinear physics-based modeling to simulate the dynamic characteristics and static response of civil infrastructure. $\mathrm{Li}$ et al. [20] proposed erosion criterion of multiscale FE model and numerical simulations of continuous RC bridge were conducted to study failure process under strong earthquake. Therefore, the multiscale FE modeling is an effective method to predict seismic collapse process of bridges.

In this paper, the authors primarily focused on (1) the coupling method of rigid surface based on a simplified multiscale FE modeling approach, where the formula of displacement coordination was developed and verified for predicting the failure of bridge structures considering both computational precision and efficiency, and (2) the seismic collapse and the local failure process analysis of bridges using the LS-DYNA software for engineering applications. The numerical results were obtained to illustrate bridge dynamic failure due to extreme earthquake loading.

\section{Rigid Surface Coupling Method}

Three kinds of elements coupling modes are applied in the practical engineering: beams to solids, beams to shells, and shells to solids. In this paper, only the coupling method of beams to solids is presented and the other coupling principles of different elements are the same. The keyword "*CONSTRAINED_NODE_RIGID_BODY" was used in the simulations to couple beams and the rigid surface of solids in the LS-DYNA software, which provided good computational stability. The principle can be described as the nodes of beam elements on the coupling surface are master nodes and the nodes from the rigid surface of solid element are slave nodes, as shown in Figure 2. It is worth mentioning that the translation and rotation degrees of freedom of rigid surface are dominated by the master nodes. Figure 3 shows the displacement coordination principles of nodes on the coupling surface under axial force and moment.

In Figure 3, node $B$ is the master node of beam element on the coupling surface, and $S_{i}(i=1,2,3, \ldots, n)$ refers to the 


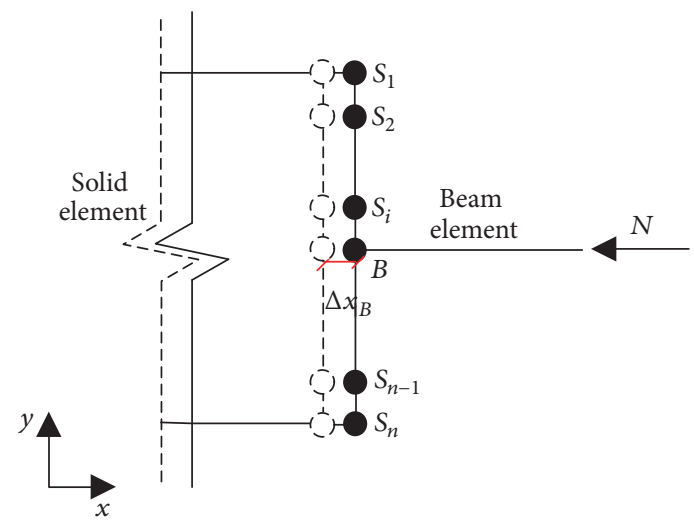

(a) Under axial force

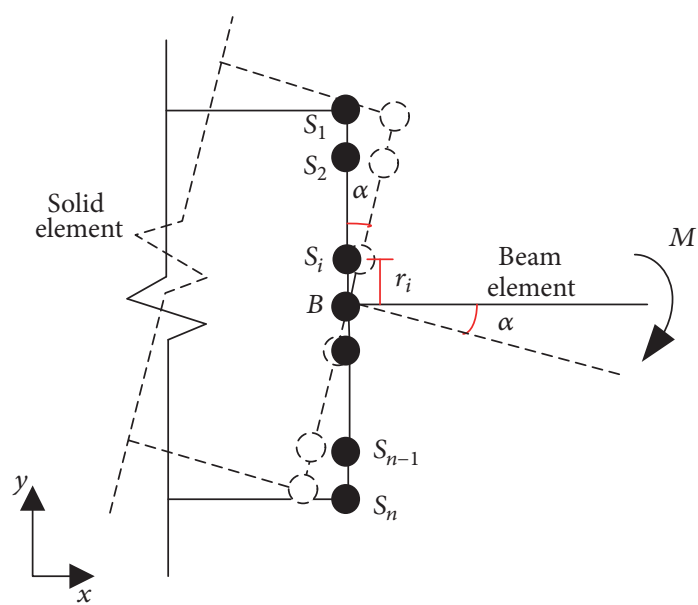

(b) Under moment

FIgURE 3: Displacement relationships of nodes on the coupling surface.

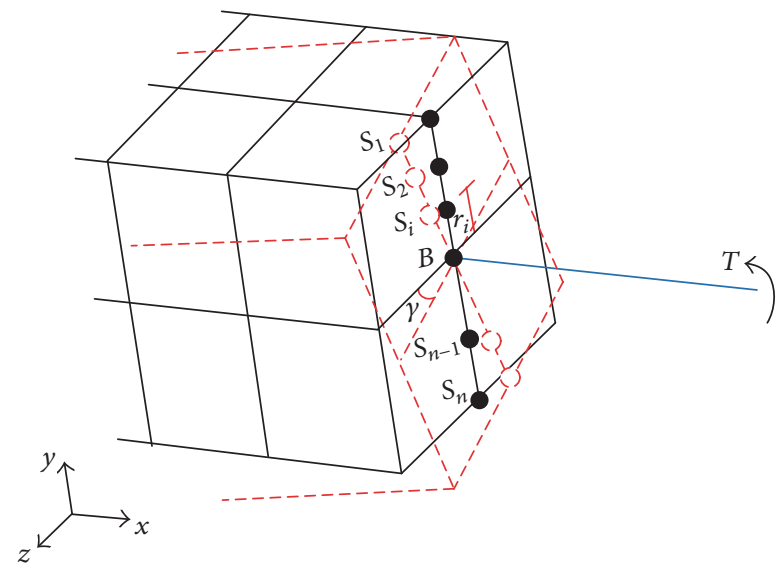

FIGURE 4: Displacement coordinate principles of nodes under torque.

slave nodes of solid element. The nodes displacements of the detailed 3D solid element satisfy the following equations:

$$
\begin{aligned}
& \Delta x_{S_{i}}=\Delta x_{B}+r_{i} \sin \alpha, \\
& \Delta y_{S_{i}}=\Delta y_{B}+r_{i}(\cos \alpha-1),
\end{aligned}
$$

where $\Delta x_{B}, \Delta y_{B}, \Delta x_{S_{i}}$, and $\Delta y_{S_{i}}$ are the displacements that belong to node $B$ of beam element and node $S_{i}$ of solid element, respectively; $\alpha$ is the rotation angle of beam element at node $B ; r_{i}$ is the distance between node $B$ and node $S_{i}$.

Figure 4 shows the displacement coordination principles of nodes on the coupling surface under torque.

In Figure 4, the displacement coordination equation can be described as follows:

$$
\begin{aligned}
\Delta y_{S_{i}} & =r_{i}(\cos \gamma-1), \\
\Delta z_{S_{i}} & =r_{i} \sin \gamma,
\end{aligned}
$$

where $\Delta y_{S_{i}}$ and $\Delta z_{S_{i}}$ are the displacements in the $y$ and $z$ directions of node $S_{i} \cdot \gamma$ is the rotation angle of the coupling surface about $x$-axis.

\section{Numerical Verification of Rigid Surface Coupling Method}

To verify the efficiency of the rigid surface coupling method based on a simplified multiscale modeling method, a singlecolumn pier and a two-span simply supported beam bridge were simulated using the detailed $3 \mathrm{D}$ FE model and the multiscale FE model.

3.1. Numerical Experiments of a Single-Column Pier. Five models were developed to illustrate the precision of the proposed method with the LS-DYNA program, including solid model (Solid 164, model 1), multiscale models (model 2-model 4), and beam model (Beam 161, model 5), as shown in Figure 5. The cross section and the height of the piers are $200 \times 200 \mathrm{~mm}$ and $2000 \mathrm{~mm}$, respectively. The length of beam elements of model 2-model 4 is $1000 \mathrm{~mm}$ but the locations of beam elements are different. The isotropic elastic constitutive relation was used in the five models. Moreover, the numerical experiments contain three parts: modal analysis, quasi-static analysis, and time history analysis. 
TABLE 1: Natural frequencies of structures (Hz).

\begin{tabular}{lccccc}
\hline Frequency & Model 1 & Model 2 & Model 3 & Model 4 & $3.97 \times 10^{1}$ \\
\hline 1 & $3.92 \times 10^{1}$ & $4.03 \times 10^{1}$ & $3.95 \times 10^{1}$ & $1.71 \times 10^{2}$ & $4.06 \times 10^{1}$ \\
2 & $1.68 \times 10^{2}$ & $1.71 \times 10^{2}$ & $1.72 \times 10^{2}$ & $2.43 \times 10^{2}$ & $2.74 \times 10^{2}$ \\
3 & $2.37 \times 10^{2}$ & $2.42 \times 10^{2}$ & $2.43 \times 10^{2}$ & $5.31 \times 10^{2}$ & $5.44 \times 10^{2}$ \\
4 & $5.18 \times 10^{2}$ & $5.30 \times 10^{2}$ & $5.31 \times 10^{2}$ & $6.32 \times 10^{2}$ \\
5
\end{tabular}

TABLE 2: Error analysis of natural frequencies (\%).

\begin{tabular}{lcccc}
\hline Frequency & Model 2 & Model 3 & Model 4 & Model 5 \\
\hline 1 & 2.70 & 0.74 & 1.15 & 3.42 \\
2 & 1.66 & 1.87 & 1.76 & 3.50 \\
3 & 1.97 & 2.51 & 2.35 & 4.45 \\
4 & 2.27 & 2.53 & 2.48 & 4.89 \\
5 & 0.54 & 0.63 & 0.67 & 0.49 \\
\hline
\end{tabular}

3.1.1. Modal Analysis. Natural frequencies are the inherent characteristic of structures, which directly affects their seismic response. Table 1 shows the natural frequencies of structures for different models. Obviously, the frequencies of multiscale models are a little higher than the solid model. Moreover, Table 2 shows the errors of natural frequencies for model 2-model 5 when compared to model 1 . The maximum error of the natural frequency is $4.89 \%$, which indicates that the dynamic property of the simplified multiscale model fits well with the solid model.

3.1.2. Quasi-Static Analysis. The pier was fixed at the bottom and a displacement and a torque were, respectively, applied on the top of the bridge pier.

(1) Applying Displacement on the Top of Bridge Pier. The solid model and multiscale models (model 1-model 4) were simulated by applying $8 \mathrm{~mm}$ linear displacement in 10 seconds. Figure 6 presents the comparison of von Mises stress between the solid model and the coupling surface of simplified multiscale model at the same position. It is observed that the stress on the coupling surface and other positions increases linearly with time, which indicates that the calculation of multiscale models is steady.

Compared with the von Mises stress of model 1, the maximum error of model 2 -model 4 on the coupling surface is $3.43 \%, 0.79 \%$, and $1.73 \%$, which indicates that the von Mises stress of multiscale models is in good agreement with that of the solid model. Figure 7 shows the stress distribution of the five models at the same time. It can be seen that the rigid surface coupling method based on a simplified multiscale modeling method is effective.

(2) Applying Torque on the Top of Bridge Pier. The contours of $Z$-coordinate of model 1 and model 3 when subjected to applied torque are shown in Figure 8. Obviously, there is a little difference between the solid model and the multiscale model under torque.
According to numerical experiment of the single-column pier, the displacement coordination principles on the coupling surface are verified under force, moment, and torque, respectively. Obviously, the rigid surface coupling method of simplified multiscale model guarantees the steadiness and precision of calculation.

3.1.3. Time History Analysis. After the modal analysis and quasi-static analysis, time history analysis was subsequently conducted to verify the reliability of the multiscale models. Figure 9 shows the loading protocol of the numerical simulation. Figure 10 shows the comparison of von Mises stress at the same position between the solid model and multiscale models. Apparently, the von Mises stress of multiscale models is in good agreement with that of the solid model.

It is notable that the computation time of $3 \mathrm{D}$ detailed model was longer than multiscale models. According to the modal analysis, quasi-static analysis, and time history analysis, it is obvious that the proposed simplified multiscale models show satisfactory precision and stability of computation in component level. Therefore, the proposed coupling method of simplified multiscale model can be used to predict the performance of structures.

\subsection{Numerical Verification of a Two-Span Simply Supported Girder Bridge}

3.2.1. Bridge Model. The time history analysis of a two-span simply supported girder bridge was conducted for validating the precision of multiscale models in structural level. Figure 11 shows the elevation view of the bridge $(30 \mathrm{~m}+30 \mathrm{~m})$, the detailed elevation view of the pier, the cross-sectional view of the box girder, and the cross-sectional view of the pier. A $60 \mathrm{~mm}$ gap was set between the two girders as well as the girder and the abutment as expansion joint to allow for contraction and expansion of bridge girders.

The solid model and the multiscale model were established based on LS-DYNA software, as shown in Figure 12. The solid elements (Solid 164) were used in the detailed area. 


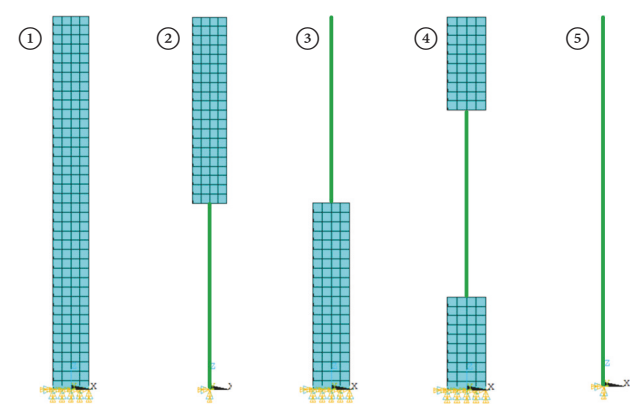

FIGURE 5: Five models of numerical simulation.

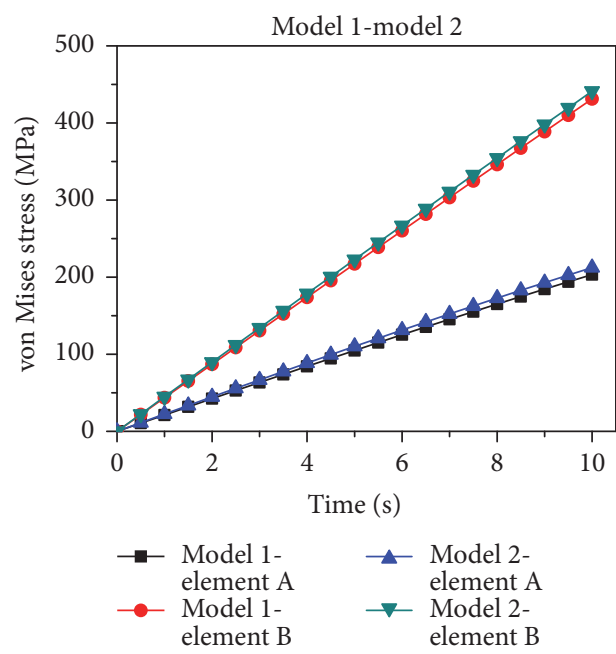

(a) Model 1 and model 2

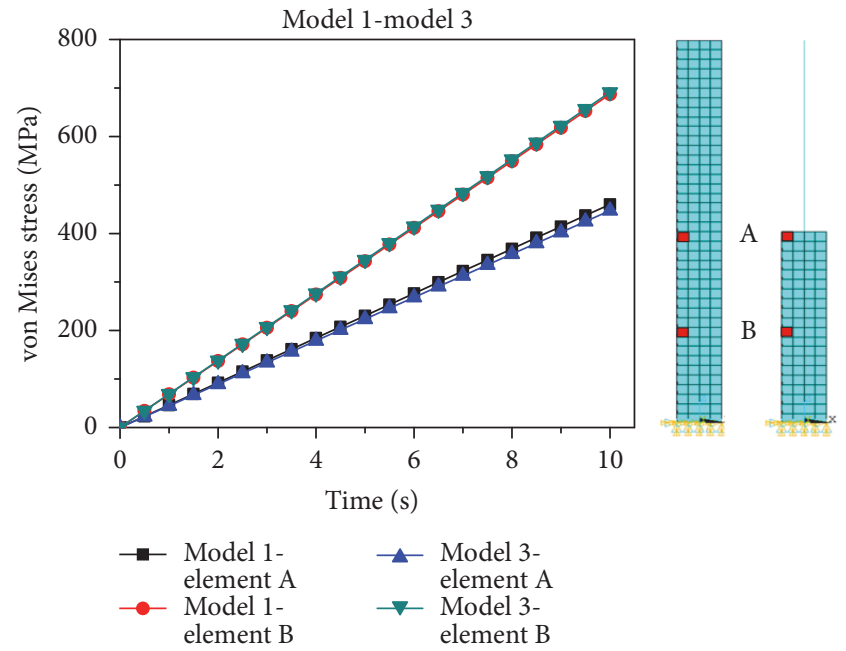

(b) Model 1 and model 3

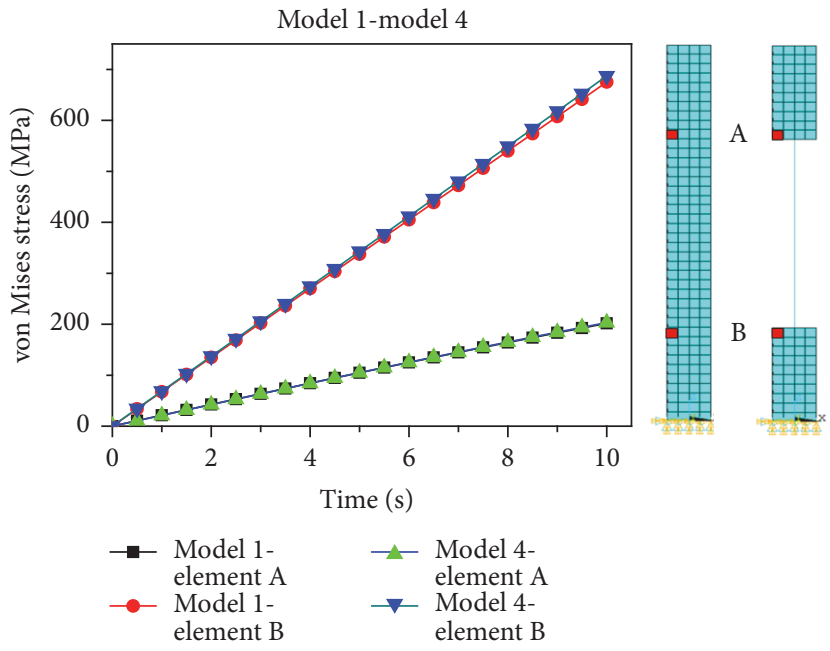

(c) Model 1 and model 4

Figure 6: The comparison of von Mises stress between different models.

In order to increase the computational efficiency, some parts were modeled by beam elements (Beam 161) in the multiscale model.

Basin rubber bearings were used in the prototype bridge, which were simulated by spring elements (Combi 165) in the simulation, as shown in Figure 13. The spring elements only transform vertical force to girders and piers. Moreover, the vertical displacement of two ends of the spring is consistent. Mechanical behavior of the basin rubber bearing was modeled by nonlinear spring constitutive model as shown in Figure 14. The failure displacement can be defined by using keyword “*SECTION_DISCRETE.” 


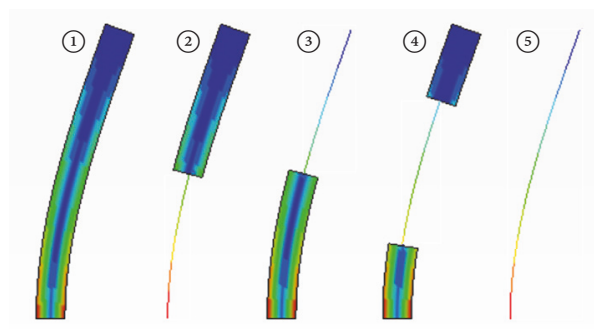

FIGURE 7: Stress distribution of five models at the same time.

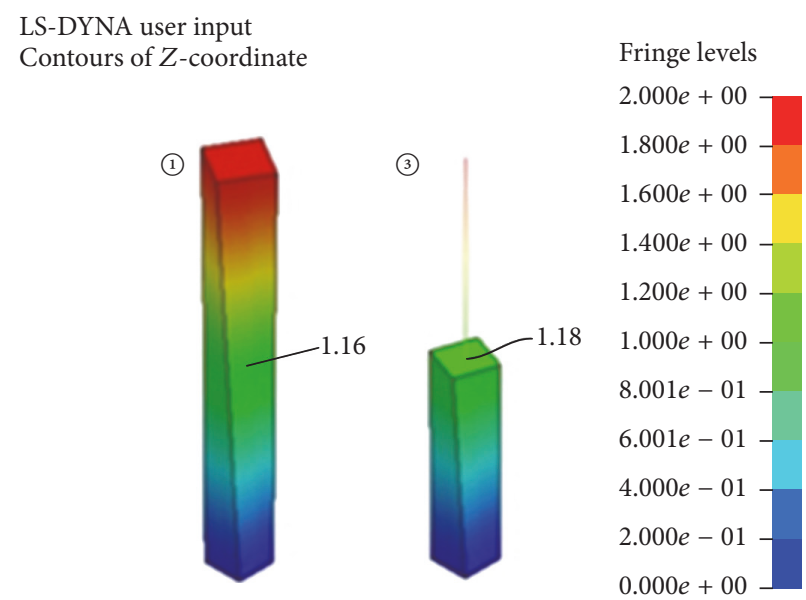

Figure 8: Contours of $Z$-coordinate of model 1 and model 3 under torque.

HJC model proposed by Holmquist and Jonson [21] was utilized to describe the constitutive relation of concrete in the present study. Grade C50 concrete and grade C30 concrete (according to the Chinese concrete grade) were used for girders and piers, respectively. The parameters of grade C50 concrete and grade C30 concrete are listed in Table 3. The numbers in the bracket are the parameters of grade C30 concrete which are individually different from the parameters of grade C50 concrete.

The El Centro ground motion was adopted as the acceleration time history curves to conduct numerical analysis, as shown in Figure 15. In order to reduce the computational time, only the first 10 seconds of the El Centro ground motion were applied at the bottom of the piers in the longitudinal direction.

3.2.2. Modal Analysis. Modal analysis is used to study the natural frequencies, which directly reflect the seismic responses of structures. Table 4 shows the values of the first eight frequencies. Obviously, the simulation results of the multiscale model are in agreement with the solid model, which validates the reliability of the simplified multiscale model.

3.2.3. Comparison of Support Reaction. The time history curves of support reaction present the positional change between the girder and the abutment with the increase of time. The bearing positions and connection surfaces are shown in Figure 16. Figure 17 shows the time history curves of support reaction between the two models, including bearing 1 , bearing 2 , bearing 3 , and bearing 4 . Figure 17(a) presents a little difference of the failure time between the solid model and multiscale model. Figure 17(b) depicts that the peak of support reaction at $1.8 \mathrm{~s}$ has slight difference between the two models. Considering the efficiency of computation, these differences are accepted in practical engineering.

3.2.4. Comparison of Pounding Forces. Figure 18 compares the pounding force time histories between the solid model and the multiscale model at different connection surfaces. Moreover, Tables 5-7 list the three main pounding forces and the corresponding time at the three connection surfaces. Comparing the pounding responses between the solid model and the multiscale model, it can be seen that the pounding responses of the two models are identical in the first five seconds. However, there is a little difference between the two models in the last five seconds. The differences are accepted compared with the reduction of computational time.

3.2.5. Comparison of Responses at the Base of Bridge Piers. The base shear forces of bridge piers directly represent the damage and failure of bridges. Figure 19 shows the comparisons of base shear force and moment of bridge piers with different models. The base shear forces and moments of the two models are essentially identical, especially in the first six seconds. The peak of base shear force and the peak of moment of the 


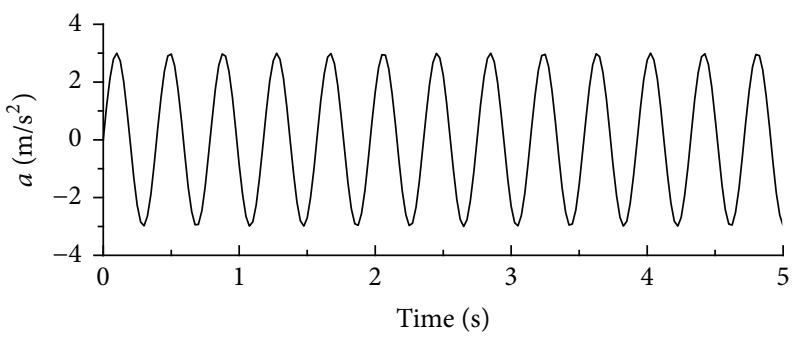

FIGURE 9: Loading protocol.
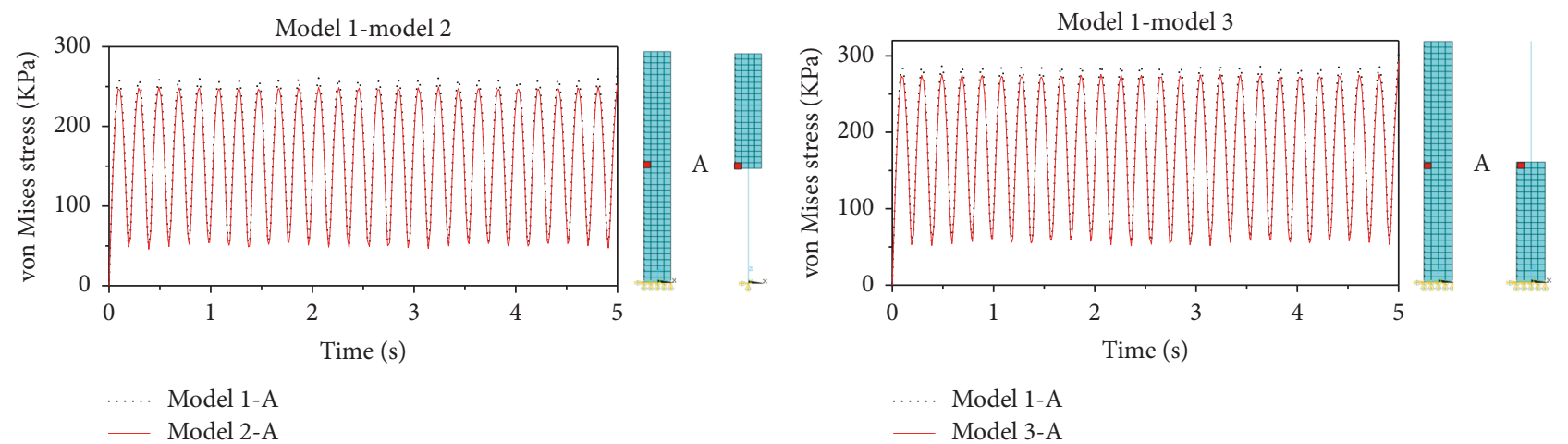

Model 1-A

— Model 3-A

(a) Model 1 and model 2 (element A)

(b) Model 1 and model 3 (element A)

Model 1-model 4 (element A)

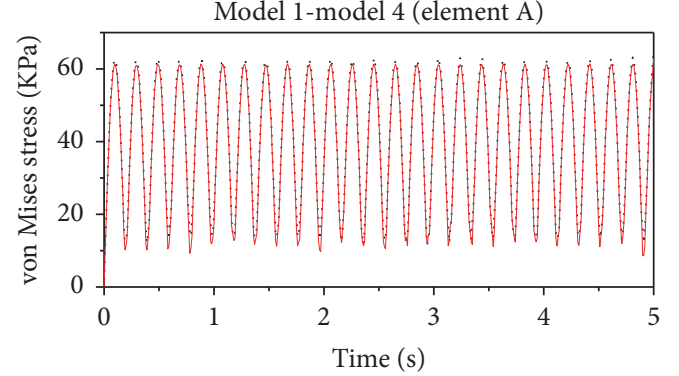

Model 1-model 4 (element B)
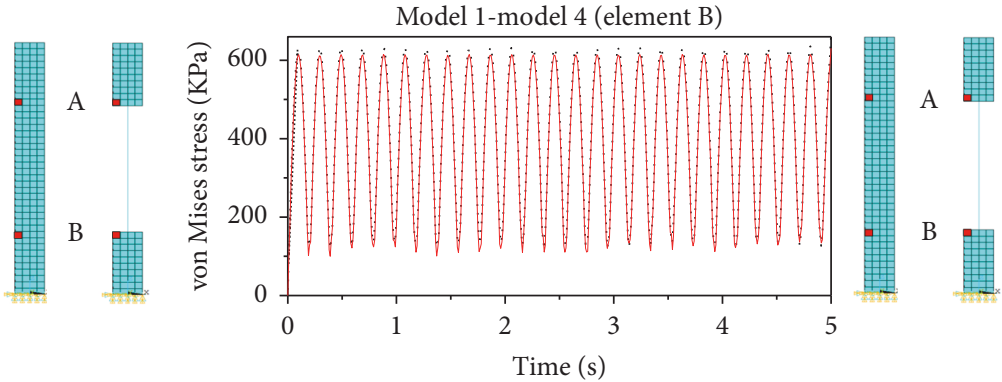

..... Model 1-A

— Model 4-A

(c) Model 1 and model 4 (element A)

_ Model 4-B

(d) Model 1 and model 4 (element B)

Figure 10: The comparison of von Mises stress.

TABLE 3: The parameters of grade C50 (C30) concrete.

(a)

\begin{tabular}{lcccccccc}
\hline & \multicolumn{8}{c}{ Parameters of strength } \\
$A$ & $B$ & $N$ & $C$ & $S M A X$ & $f_{c} / \mathrm{MPa}$ & $\dot{\varepsilon}_{0} / \mathrm{s}^{-1}$ & $T / \mathrm{MPa}$ & G/GPa \\
\hline 0.79 & 1.60 & 0.61 & 0.007 & 7.00 & $48(30)$ & 1.0 & $4.00(3.39)$ & 12.5 \\
\hline
\end{tabular}

(b)

\begin{tabular}{lcc}
\hline & Parameters of damage & EFMIN \\
\hline$D_{1}$ & $D_{2}$ & 0.01 \\
\hline
\end{tabular}

(c)

Parameters of state equation

\begin{tabular}{lcccccc}
$\mu_{\text {crush }}$ & $\mu_{\text {lock }}$ & $P_{\text {crush }} / \mathrm{MPa}$ & $P_{\text {lock }} / \mathrm{MPa}$ & $K_{1} / \mathrm{GPa}$ & $K_{2} / \mathrm{GPa}$ & $K_{3} / \mathrm{GPa}$ \\
\hline $0.001\left(4.73 \times 10^{-4}\right)$ & $0.1(0.073)$ & $16(10)$ & 800 & 85 & -171 & 208 \\
\hline
\end{tabular}




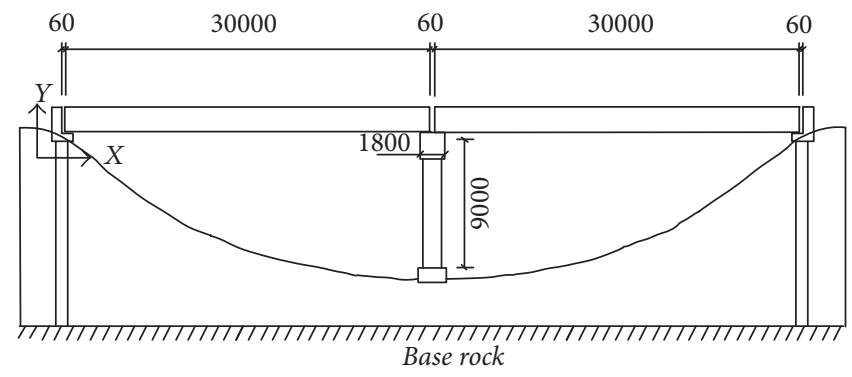

(a) The elevation view of bridge

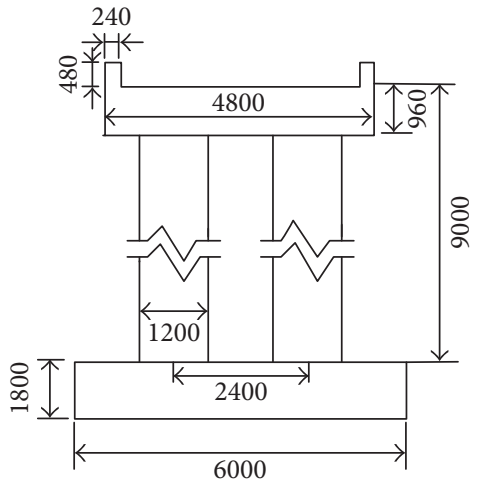

(b) Elevation view of pier

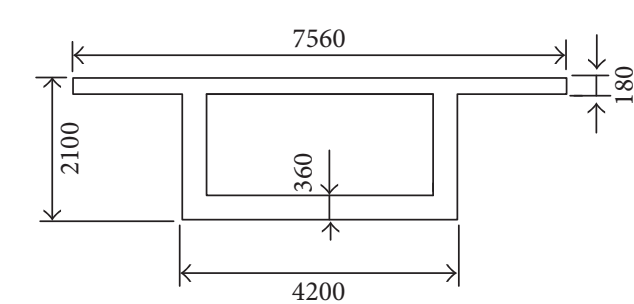

(c) Cross-sectional view of box girder

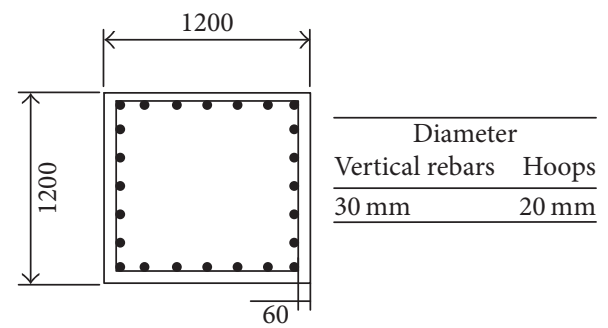

(d) Cross-sectional view of pier

FIGURE 11: Sketch map of a two-span simply supported girder bridge.

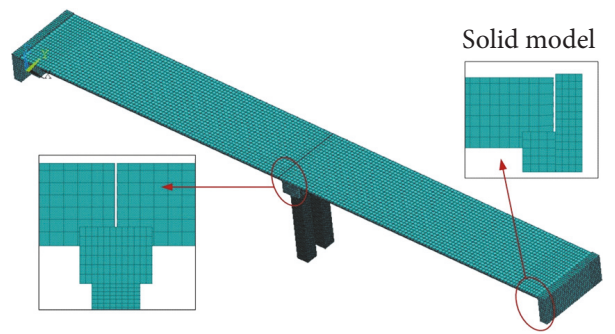

(a) The solid model

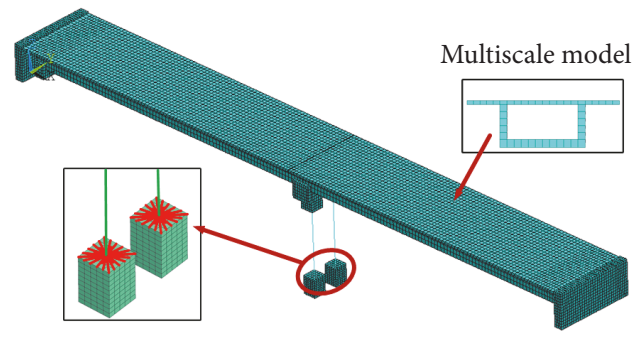

(b) The multiscale model

Figure 12: The model of bridge.

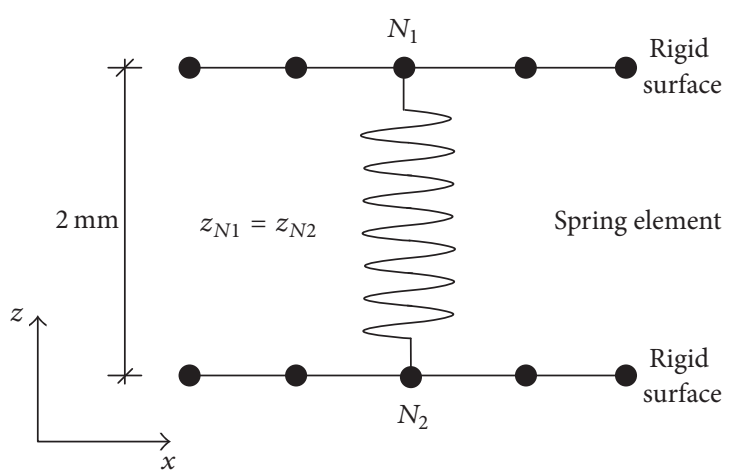

FIgURE 13: Numerical simulation method of the bearing. 


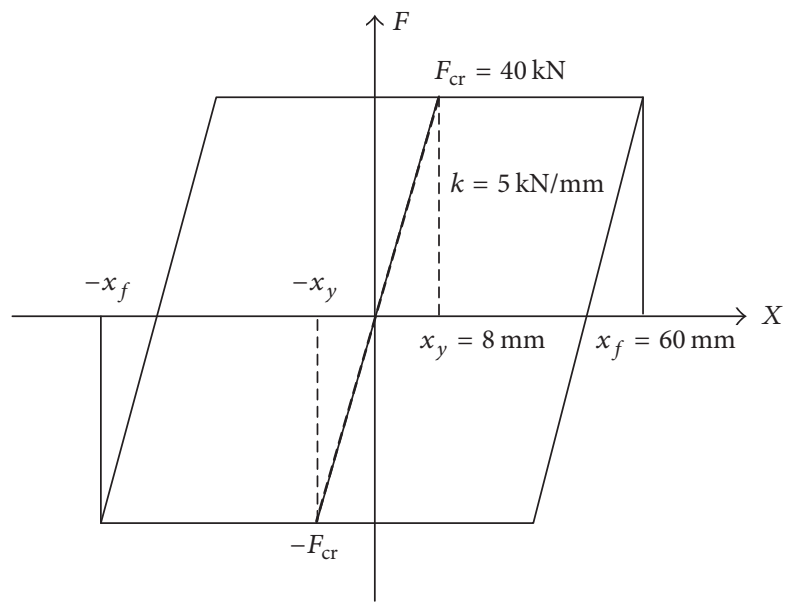

FIGURE 14: Nonlinear spring constitutive model.

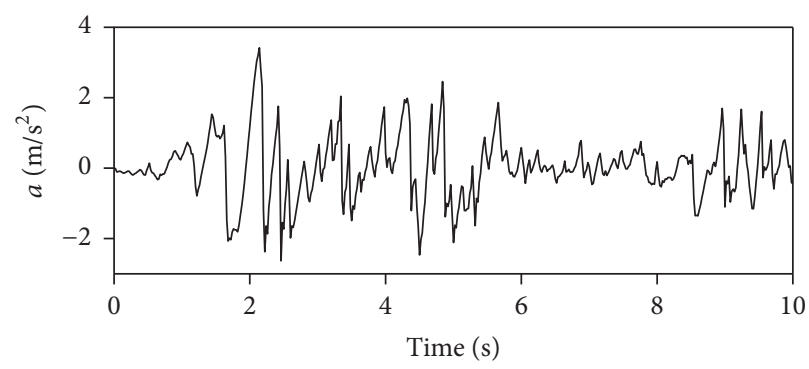

Figure 15: El Centro ground motion.

TABLE 4: The values of the first eight frequencies (Hz).

\begin{tabular}{lccccccrr}
\hline Frequency & 1 & 2 & 3 & 4 & 5 & 6 & 7 & 8 \\
\hline $\begin{array}{l}\text { Solid model } \\
\begin{array}{l}\text { Multiscale } \\
\text { model }\end{array}\end{array}$ & 6.139 & 7.140 & 7.690 & 8.136 & 8.398 & 8.430 & 8.506 \\
\hline
\end{tabular}

TABLE 5: Pounding forces and the corresponding time at \#1 connection surface.

\begin{tabular}{lcccccc}
\hline Model type & 1 & & & 2 & 3 & \\
& Pounding force $(\mathrm{kN})$ & Time $(\mathrm{s})$ & Pounding force $(\mathrm{kN})$ & Time $(\mathrm{s})$ & Pounding force $(\mathrm{kN})$ & Time $(\mathrm{s})$ \\
\hline Solid model & 15170 & 5.885 & 14470 & 2.205 & 7830 & 3.230 \\
Multiscale model & 17120 & 5.680 & 14200 & 2.195 & 7190 \\
\hline
\end{tabular}

TABLE 6: Pounding forces and the corresponding time at \#2 connection surface.

\begin{tabular}{lcccccc}
\hline Model type & 1 & & 2 & 3 & & \\
& Pounding force $(\mathrm{kN})$ & Time $(\mathrm{s})$ & Pounding force $(\mathrm{kN})$ & Time $(\mathrm{s})$ & Pounding force $(\mathrm{kN})$ & Time $(\mathrm{s})$ \\
\hline Solid model & 14540 & 2.535 & 9930 & 2.660 & 8060 & 6.140 \\
Multiscale model & 16330 & 2.525 & 12670 & 3.550 & 10430 \\
\hline
\end{tabular}

TABLE 7: Pounding forces and the corresponding time at \#3 connection surface.

\begin{tabular}{lcccccc}
\hline Model type & 1 & & & 2 & 3 & \\
& Pounding force $(\mathrm{kN})$ & Time $(\mathrm{s})$ & Pounding force $(\mathrm{kN})$ & Time $(\mathrm{s})$ & Pounding force $(\mathrm{kN})$ & Time $(\mathrm{s})$ \\
\hline Solid model & 21390 & 2.595 & 10190 & 5.105 & 9670 & 2.780 \\
Multiscale model & 23550 & 2.640 & 9590 & 4.920 & 7270 & 5.510 \\
\hline
\end{tabular}




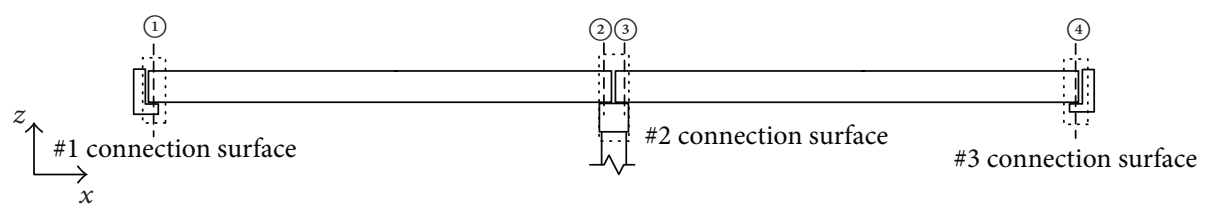

FIgURE 16: Positions of bearings and connection surfaces.

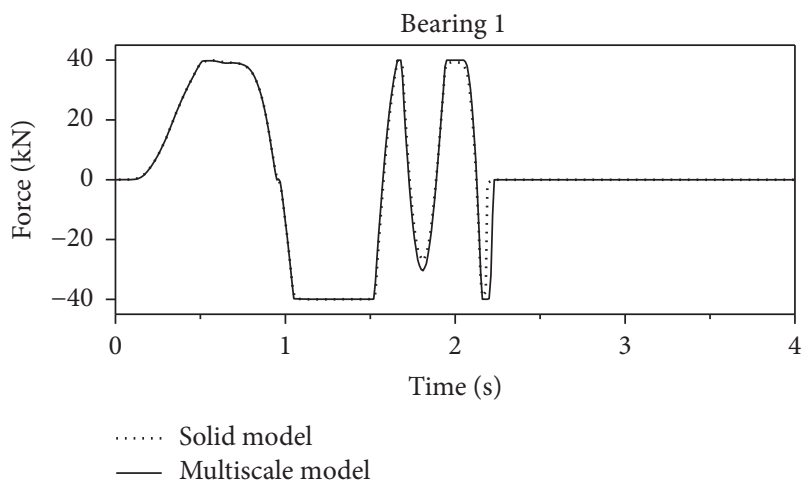

(a) Bearing 1

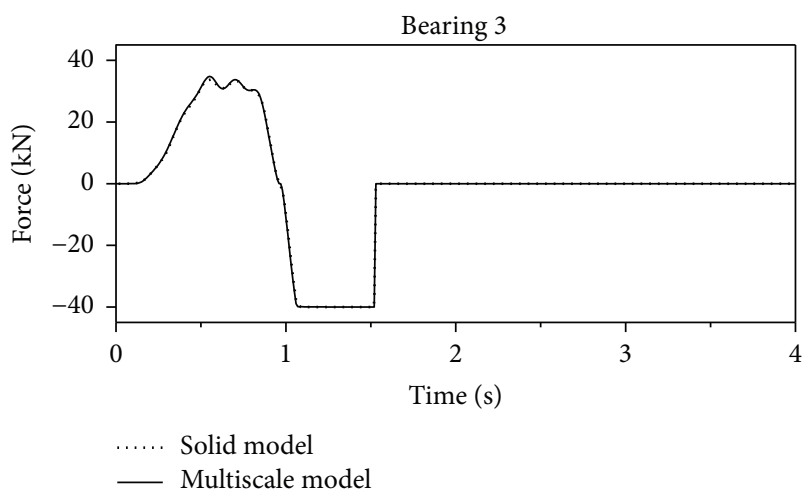

(c) Bearing 3

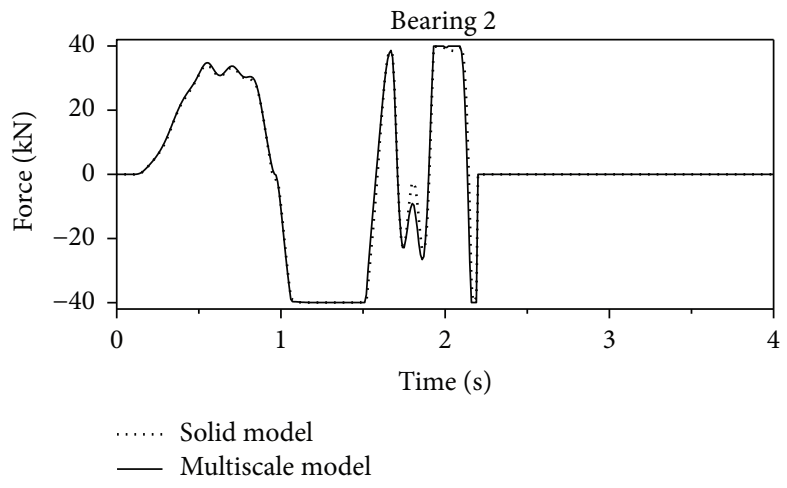

(b) Bearing 2

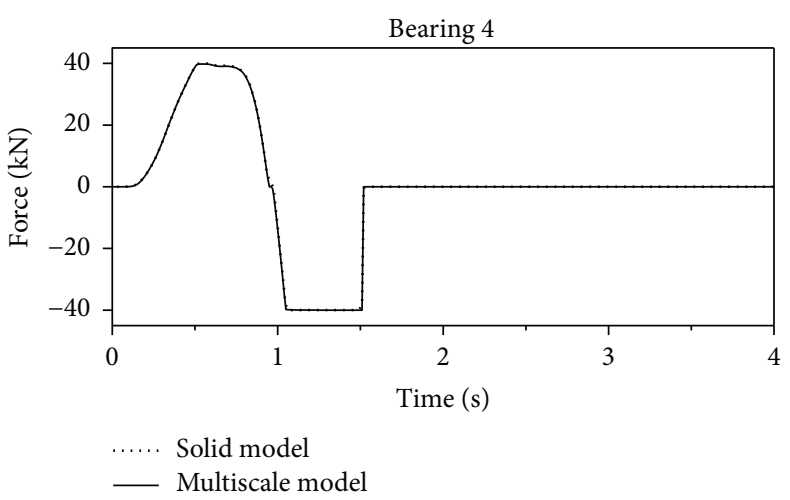

(d) Bearing 4

FIgURE 17: Time history curves of support reaction.

multiscale model are $12.6 \%$ and $8.7 \%$ higher than those of the solid model, respectively. The main reason for the difference is that the elastic constitutive relation was utilized for beam element of multiscale model and the damage constitutive relation was used for concrete of solid model; therefore, the pier of multiscale model is stiffer than that of the solid model. The comparison of stress distribution at the base of piers under the peak moment is shown in Figure 20. It can be seen that the stress distribution of multiscale model is approximately in accordance with that of the solid model.

\subsubsection{Comparison of Computational Efficiency. According} to the numerical experiment of single-column pier and a two-span simply supported girder bridge, the effectiveness of simplified multiscale modeling approach was verified. According to Table 8, it is apparent that the multiscale model is more efficient than the solid model. Although there is a little difference between the two models, the precision of the simplified multiscale model is accepted in practical engineering.

\section{Case Studies}

4.1. Collapse Analysis of a Multispan Simply Supported Girder Bridge. A multispan simply supported girder bridge was collapsed in the Wenchuan earthquake; the collapse analysis of this bridge was conducted using LS-DYNA program based on simplified multiscale modeling approach. Figure 21 presents the elevation view of the bridge and the detailed view of the bridge pier, cap beam, and girder. The effect of structure-pier-soil interaction was not considered.

The vulnerable parts of the bridge were established by solid elements, including cap beams, base of piers, top of piers, collar beams, and the end of girders. Beam elements were used in other parts of the bridge to increase the efficiency of computation. The multiscale model of the bridge is shown in Figure 22. 


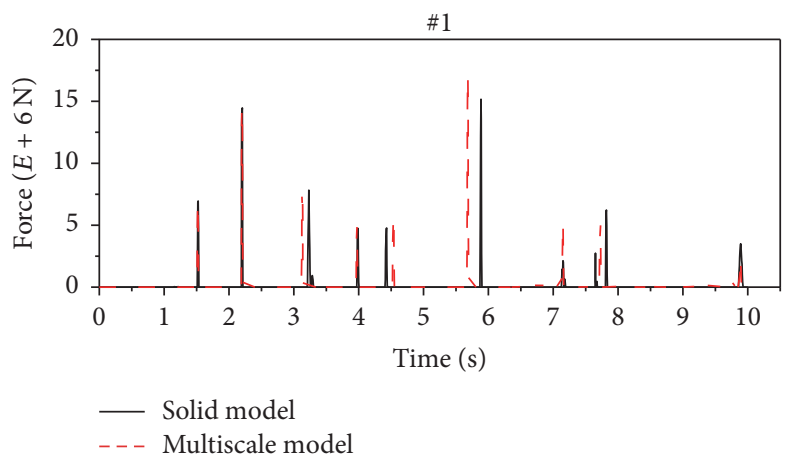

(a) \#1 connection surface

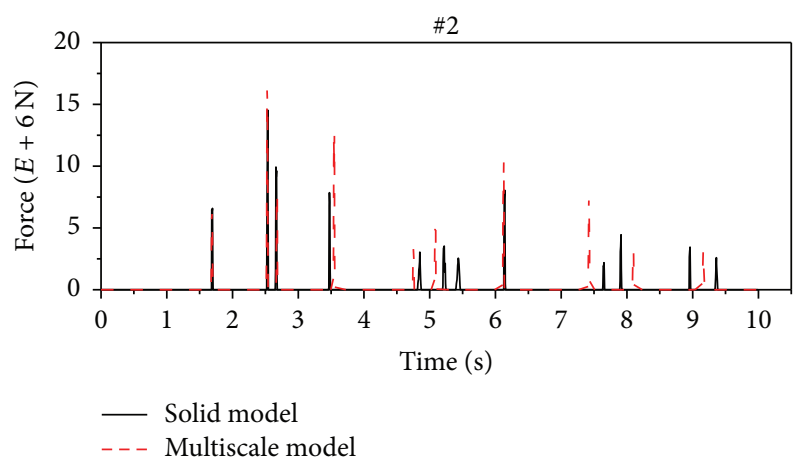

(b) \#2 connection surface

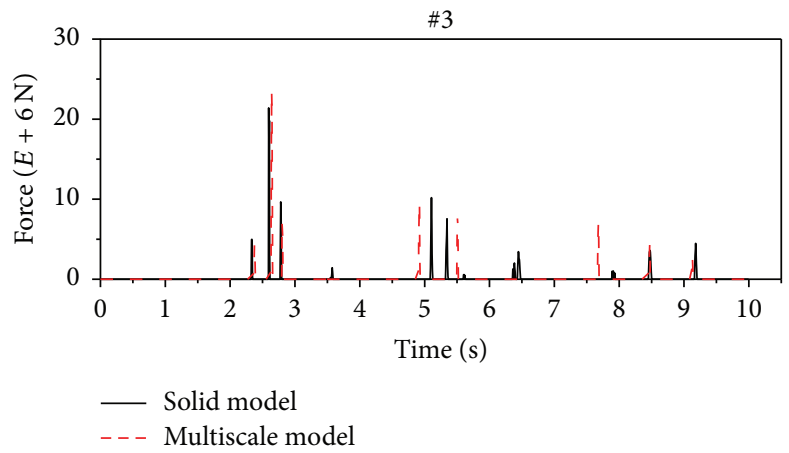

(c) \#3 connection surface

FIGURE 18: Comparison of pounding process at the three connection surfaces.

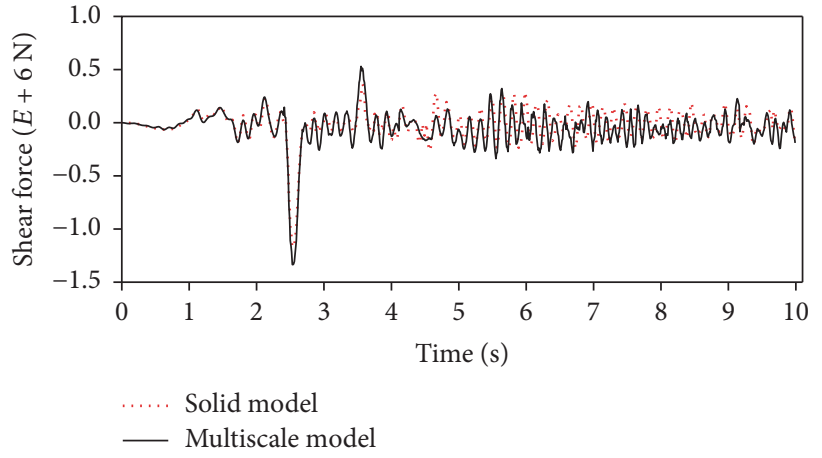

(a) Shear force

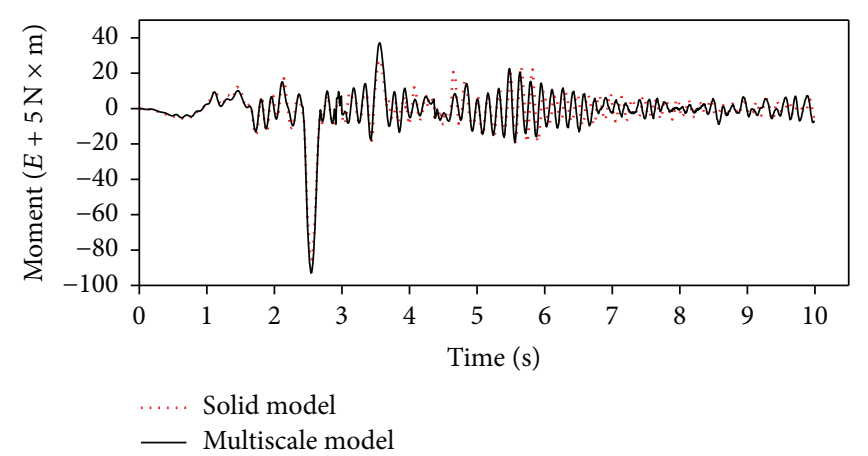

(b) Moment

FIGURE 19: Comparisons of responses at the base of piers with different models.

The material constitutive relation of concrete utilized the HJC model, as shown in Table 3. The rubber bearings were established by solid models, and "**MAT_ MOONEY_RIVLIN_RUBBER" was used as material constitutive relation of rubber. Seventeen seconds (36s-53s) of actual seismic record of Wenchuan earthquake through filtering was adopted as earthquake input [22].

Figure 23 shows the detailed damage and collapse process of the bridge. Obviously, the failure of A2 abutment results in the girders of the forth span falling down under pounding force. The collapse mode conducted by the numerical simulation in this paper is consistent with the real bridge collapse in Wenchuan earthquake.
Figures 24 and 25 show the pounding force and velocity of the girder on the forth span to present the demolishing process, respectively. Poundings result in cracks and failure of A2 abutment at 4 seconds. Poundings lead to most girders of the forth span successively falling down at 8 seconds. Finally, the pounding force and velocity of girder reach peak values of $2330 \mathrm{kN}$ and $1.46 \mathrm{~m} / \mathrm{s}$, respectively, which induce to all girders of the forth span dropped down to the ground.

4.2. Collapse Analysis of RC Continuous Rigid Frame Bridge. The length of the four-span RC continuous rigid frame bridge is $450 \mathrm{~m}$. A $360 \mathrm{~mm}$ expansion joint was designed between the girders and the abutments. The elevation view of bridge 


\begin{abstract}
LS-DYNA user input
Time $=2.54$

Contours of effective stress (v-m)
\end{abstract}

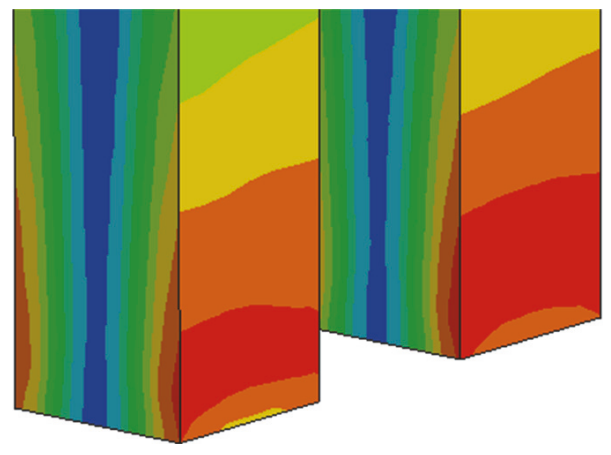

Solid model
LS-DYNA user input

Time $=2.5425$

Contours of effective stress (v-m)

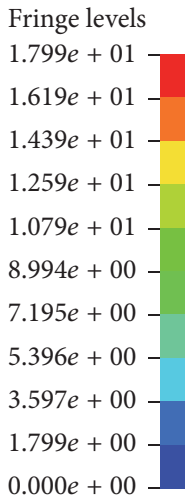

$0.000 e+00$

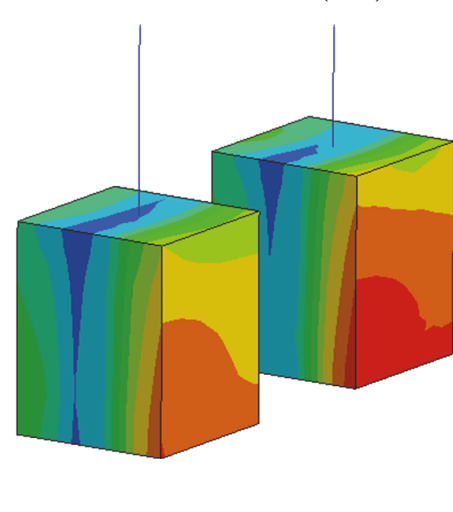

Multiscale model

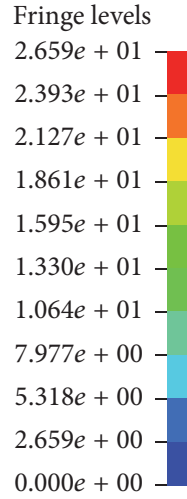

$0.000 e+00$

FIgURE 20: Stress distribution at the base of piers under the peak moment.

TABLE 8: Computation of computational efficiency of different model.

\begin{tabular}{lcc}
\hline & $\begin{array}{c}\text { The number of } \\
\text { elements }\end{array}$ & $\begin{array}{c}\text { Computational } \\
\text { time (s) }\end{array}$ \\
\hline Solid model & 20532 & 13028 \\
Multiscale model & 13046 & 6707 \\
\hline
\end{tabular}

structure and cross-sectional view of A-A and B-B are shown in Figure 26.

The solid elements were used to simulate concrete in the detailed area, including the top and the bottom of bridge piers and the end of main girder and abutments. Other parts of the bridge were established by beam elements to reduce the cost of computation. For solid elements, the HJC material constitutive relation [21] was used to model the concrete response; the parameters of grade $\mathrm{C} 50$ concrete are listed in Table 3. "**MAT_CSCM_CONCRETE” model was used for shear keys and the backwall of abutments. The multiscale model of bridge is shown in Figure 27.

4.2.1. Selection of Ground Motion Records. Figure 28 presents the first ten modes of bridge to display the dynamic characteristics. The first mode is in the longitudinal direction, and the primary mode in the transverse direction is the second mode, while the third and subsequent modes are a combination of longitudinal and transverse modes.

According to the dynamic characteristics of the bridge, actual earthquake records during the 1999 Chi-Chi earthquake were selected to simulate earthquake-induced collapse of the continuous rigid frame bridge. The effect of bidirectional earthquake was taken into account by inputting seismic waves in both the longitudinal and the transverse directions, as shown in Figure 29. The uppermost $20 \mathrm{~s}$ of the acceleration history was utilized to simulate the failure process of the bridge structure to enhance computational efficiency. The peak ground acceleration is $1.12 \mathrm{~m} / \mathrm{s}^{2}(t=9.3 \mathrm{~s})$ in the longitudinal direction and $0.85 \mathrm{~m} / \mathrm{s}^{2}(t=2.74 \mathrm{~s})$ in the transverse direction.
4.2.2. Elastic Time History Analysis. To verify the rationality of the simplified multiscale model under the selected seismic wave, the elastic time history analysis was conducted. Elastic material constitutive models were selected for the model and the pounding effects between the girders and abutments were not taken into consideration.

Figure 30 shows the relative displacement at the top of piers in the longitudinal and transverse directions. The peak displacement in the longitudinal direction is $189.6 \mathrm{~mm}$ at $8.83 \mathrm{~s}$ and the time is consistent with the time of the peak acceleration of ground motion in longitudinal direction. Obviously, the displacement tendencies of different bridge piers are the same in the longitudinal direction without consideration of traveling wave effect. Seismic response of the bridge in the longitudinal direction is primarily dominated by the first mode.

In the transverse direction, peak displacements at the top of the three piers are $75.8 \mathrm{~mm}(t=8.30 \mathrm{~s}), 136.9 \mathrm{~mm}$ $(t=8.25 \mathrm{~s})$, and $87.3 \mathrm{~mm}(t=8.36 \mathrm{~s})$, as shown in Figure $30(\mathrm{~b})$. The times corresponding to the peak displacement are approximately equal for different bridge piers. Moreover, the values of the peak displacements are related to the height of piers. Seismic response of the bridge in the transverse direction is mainly dominated by the second mode.

The elastic time history analysis has proven that seismic response of the bridge is mainly dominated by the first or second mode. Therefore, the multispan model is reliable to simulate the collapse process of bridge. 


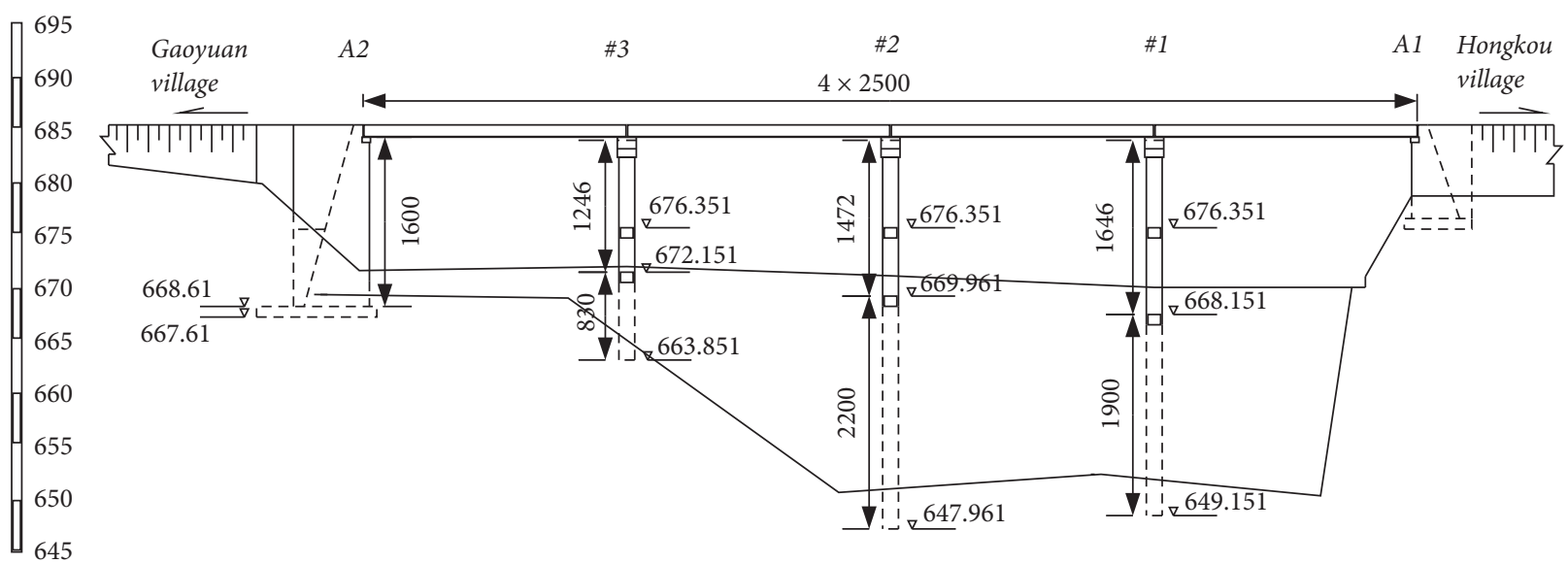

(a) The elevation view of the bridge
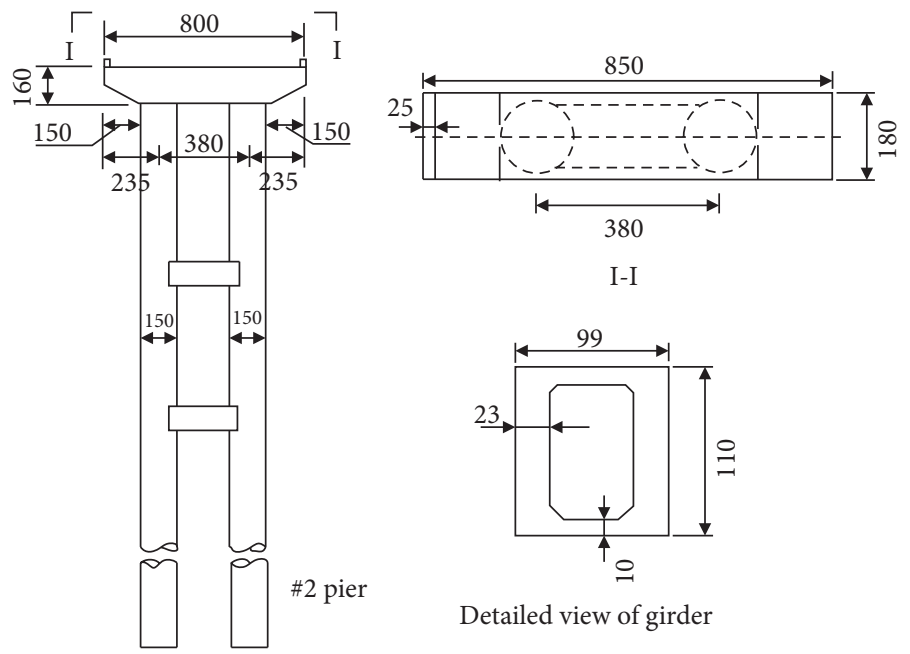

(b) Detailed view of bridge

FIGURE 21: Sketch map of bridge.

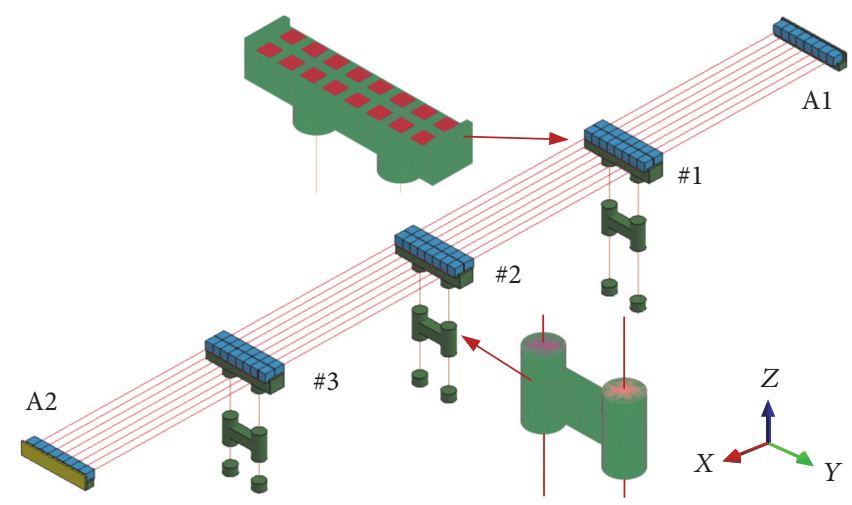

FIgURE 22: The multiscale model of the bridge.

4.2.3. Simulation of Collapse Process. In this bridge, contact problems were controlled by keyword "* CONTACT AUTOATIC_SINGLE_SURFACE" based on the penalty function method. The erosion criterion of elements was defined by keyword “"MAT_ADD_EROSION," which was used to rule out elements that have no contribution to resisting earthquake loading. Failure of concrete was controlled by the failure mode of tension and pressure. Failure parameter of the first principal strain is 0.002 and that of the third principal strain is -0.005 . Besides, the failure strain of reinforcement is 0.12 . 


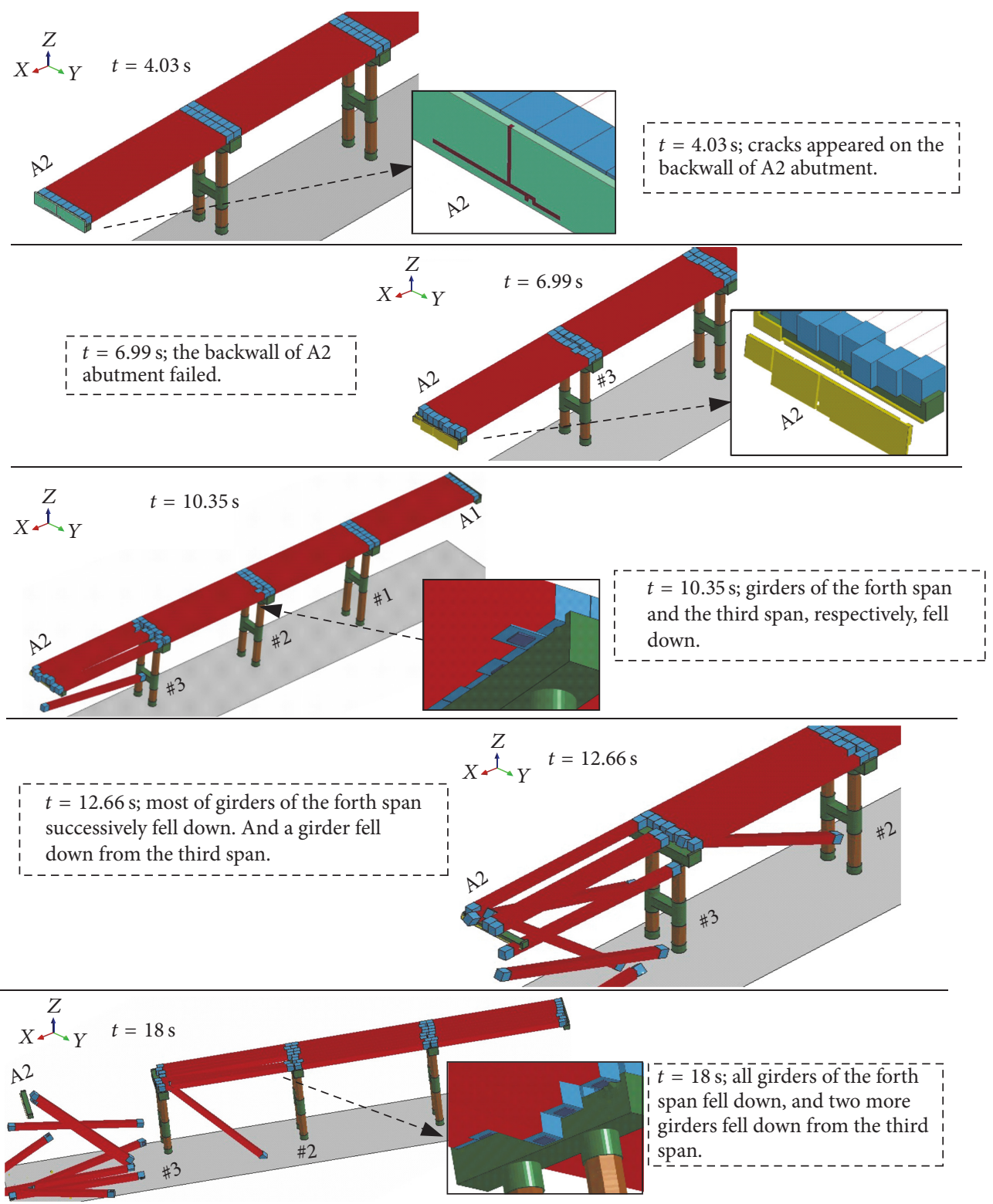

FIGURE 23: The collapse process of bridge.

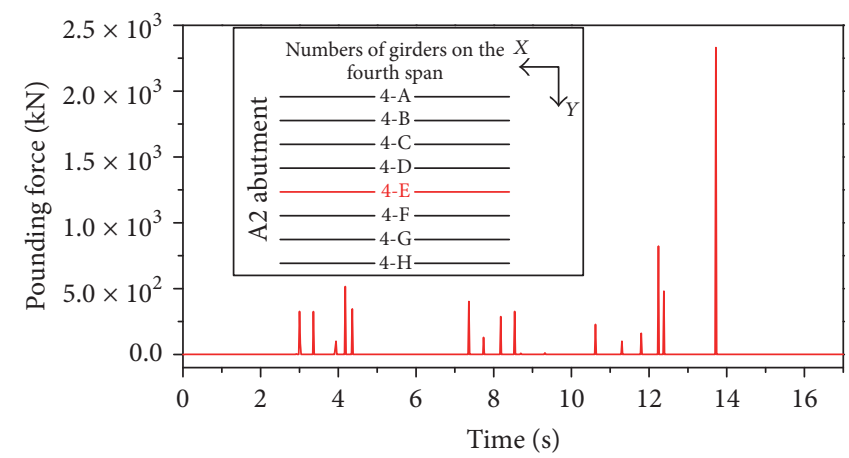

FIgURE 24: The pounding force of girder (4-E). 


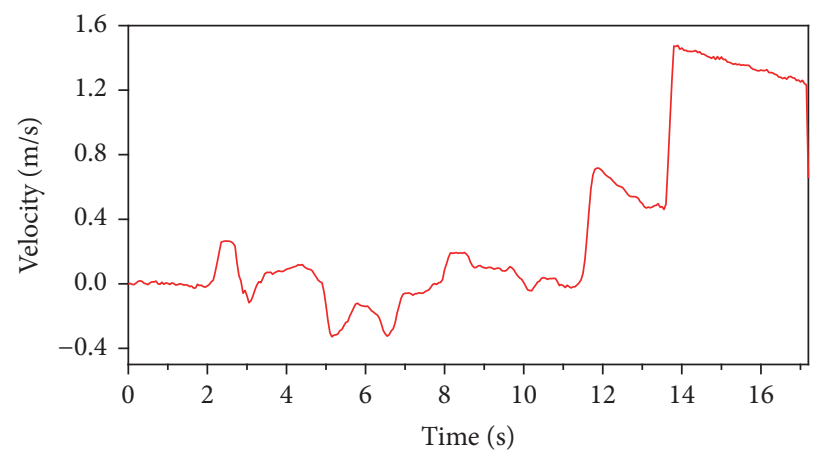

FIGURE 25: The velocity of girder (4-E).

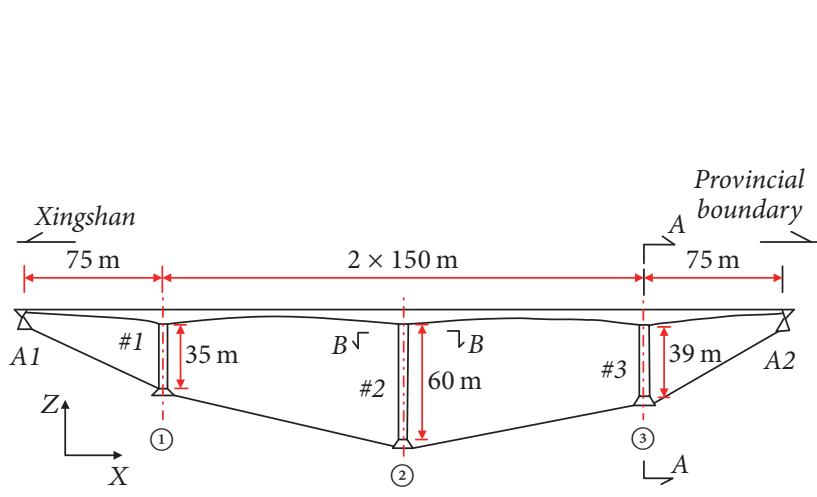

(a) The elevation view of bridge

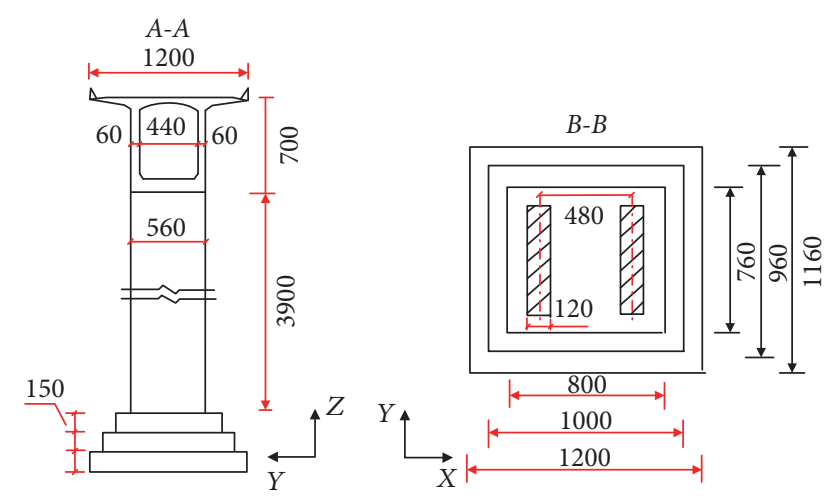

(b) The cross-sectional view of A-A and B-B

FIGURE 26: Sketch map of RC four-span continuous rigid frame bridge.

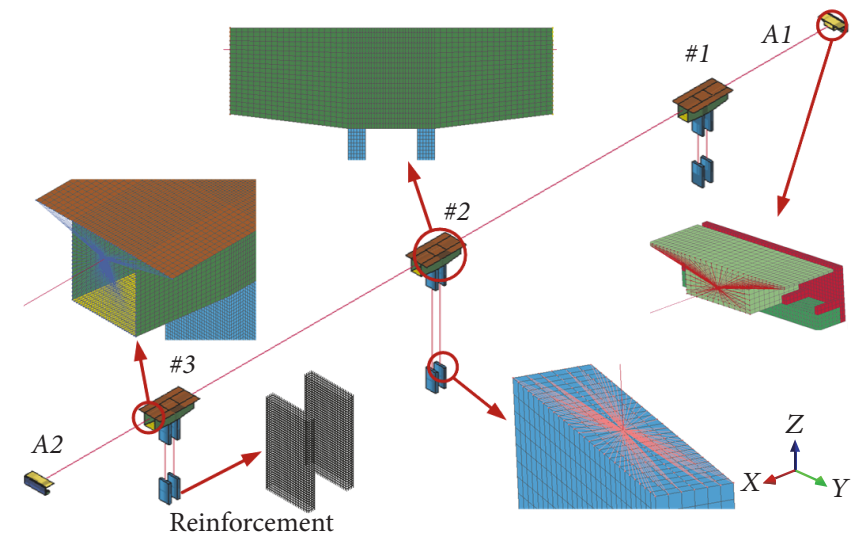

FIGURE 27: The multiscale model of the bridge.

In order to simulate the collapse process, the peak ground acceleration in the longitudinal direction and transverse direction is $3.19 \mathrm{~m} / \mathrm{s}^{2}$ and $2.42 \mathrm{~m} / \mathrm{s}^{2}$, respectively. The whole collapse process sustains $12.5 \mathrm{~s}$; the mode of collapse and local failure are shown in Figure 31.

Figure 31 shows the seismic collapse process of the whole bridge at $0 \mathrm{~s}$ and $2 \mathrm{~s}$. It can be seen that the cover concrete at the corner of piers ( $\# 1$ and $\# 3$ ) got damaged in $2 \mathrm{~s}$; stress concentration appeared between the start element and the pier. Moreover, \#2 pier was intact because the stiffness of \#2 pier is small.

The status of bridge at $4 \mathrm{~s}$ and $6 \mathrm{~s}$ is shown in Figure 32. At 4 seconds, the cover concrete cracked at the top and base of $\# 2$ pier. For \#1 and \#3 piers, the cover concrete in the plastic hinge regions mostly failed and the concrete core went into plastic state gradually.

At 6 seconds, plastic hinges appeared at the top and base of \#3 pier and \#3 pier leaned to Al abutment at an angle 


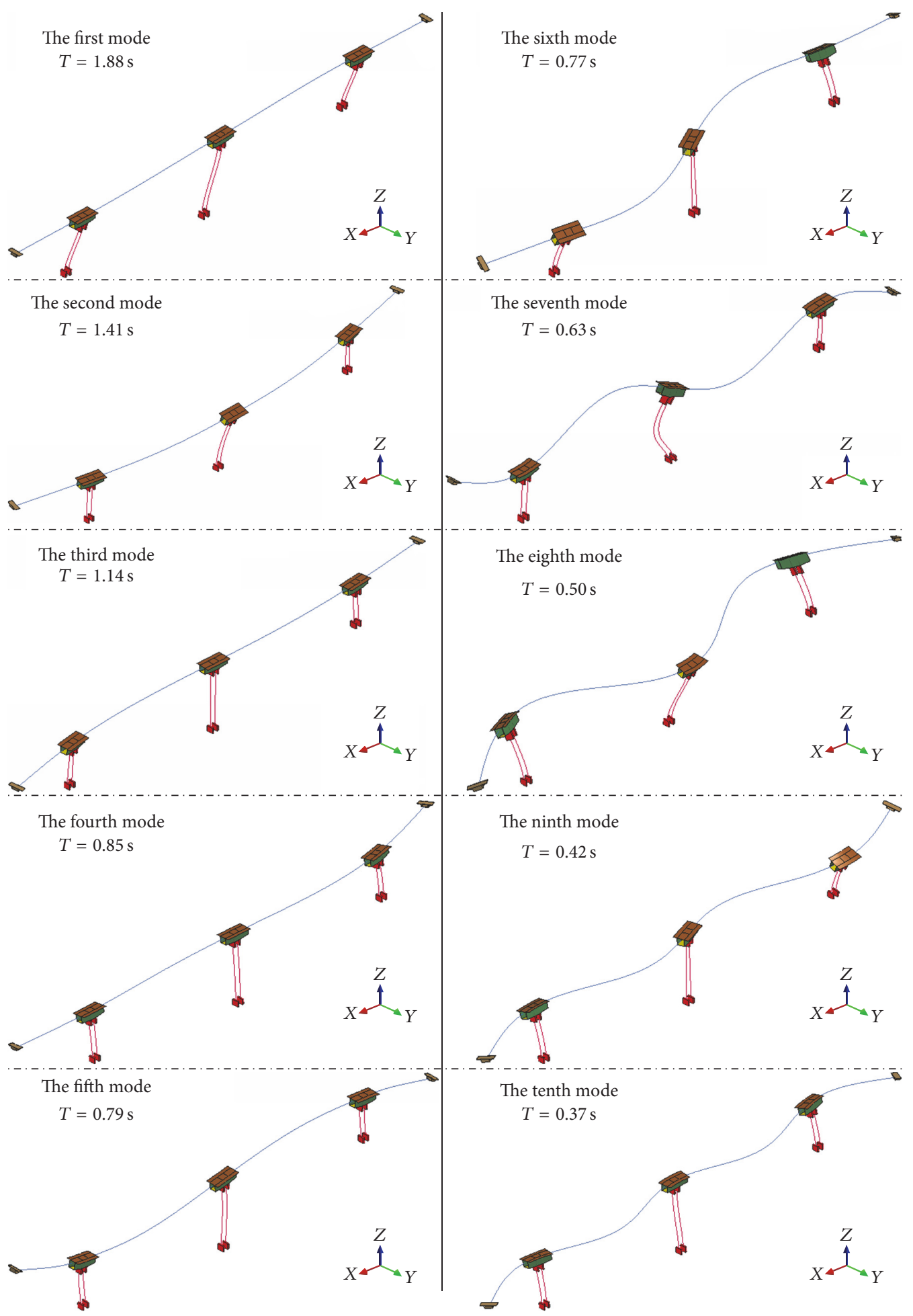

FIgURE 28: The first ten modes of the bridge.

of 1.8 degrees, which made the forth girder fell off from A2 abutment. \#2 pier still possessed great capacity and good performance in resisting the transverse force because the stiffness of pier is small, which limited the lean of \#1 pier.

At 8 seconds, the forth girder became cantilever beam due to the failure of A2 abutment, as shown in Figure 33. For \#3 pier, damage occurred on the top deck and base deck of start element and the lean of pier appeared. Lean of \#1 pier and \#2 pier was not observed and the first girder was still safe.

At 10 seconds, the forth girder broke off at start element. \#3 pier lost its capacity completely and the third girder became cantilever beam gradually. Under the interaction of 


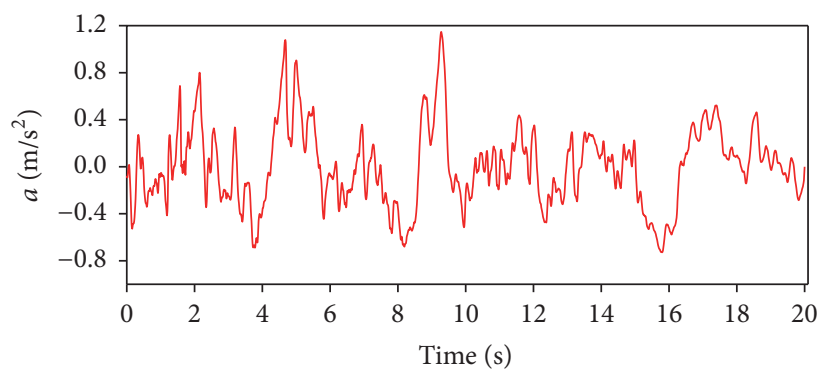

(a) Longitudinal direction

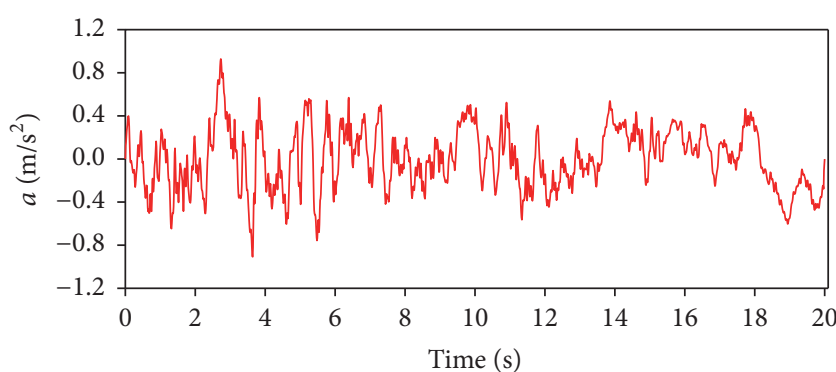

(b) Transverse direction

FIgURE 29: Ground motion record.

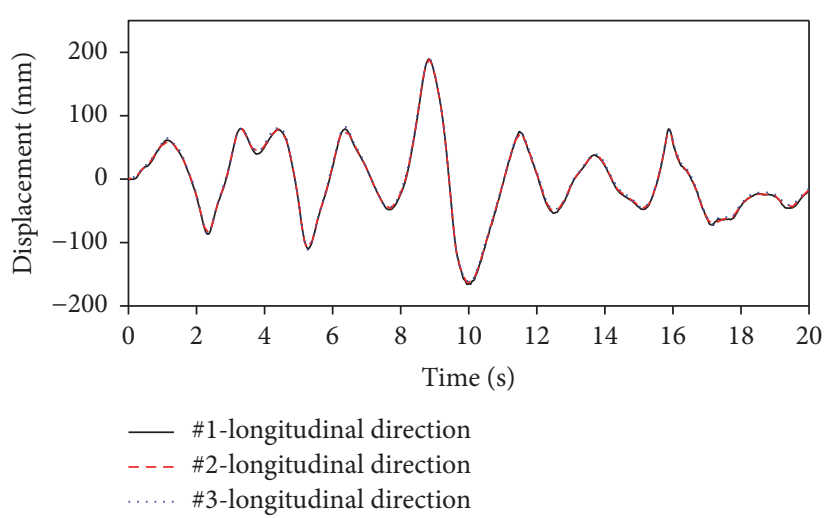

(a) In the longitudinal direction

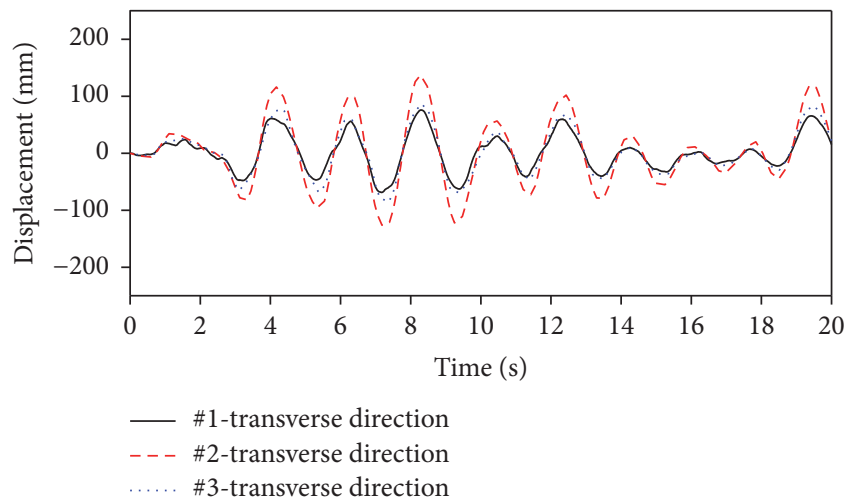

(b) In the transverse direction

FIGURE 30: Relative displacement at the top of the piers.

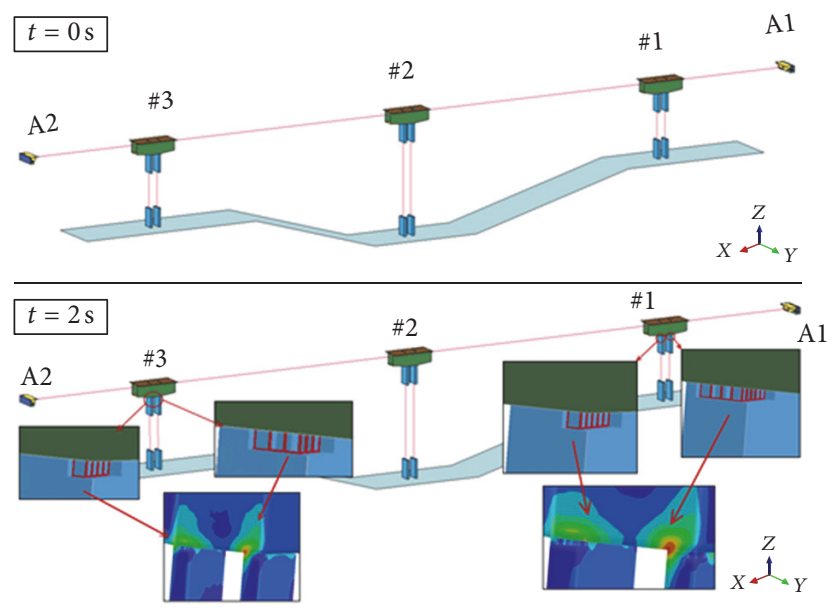

Figure 31: Collapse process of the bridge ( $t=0 \mathrm{~s}$ and $t=2 \mathrm{~s})$.

earthquake force and collapse effect, plastic hinges appeared at \#1 pier and leaned to A2 abutment with an angle of 5 degrees. Moreover, plastic hinges occurred at the base of \#2 pier at a space of $1.7 \mathrm{~m}$ and leaned to A2 abutment with an angle of 2.2 degrees. Apparently, the whole bridge presented unstable status.

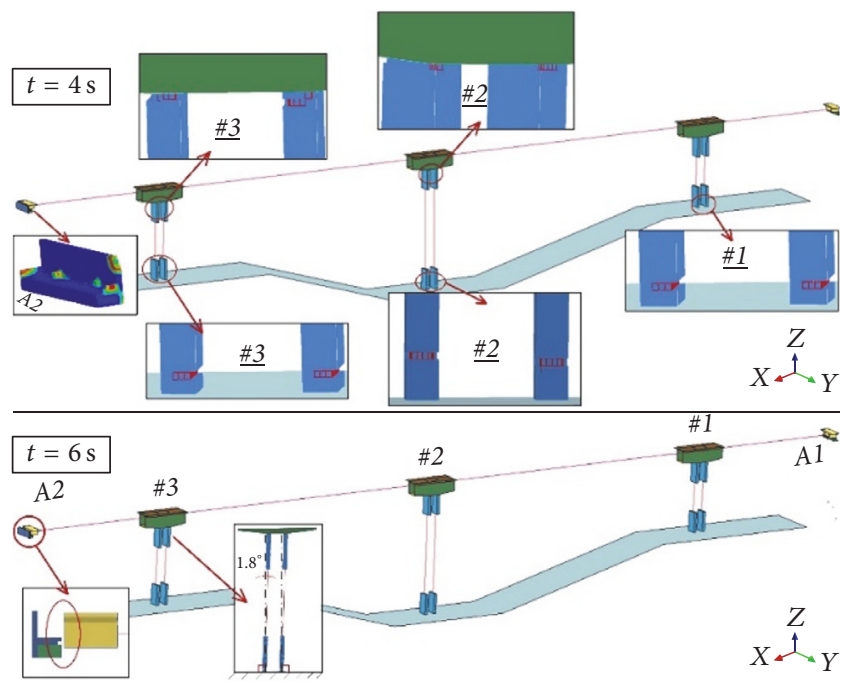

FIGURE 32: Collapse process of the bridge ( $t=4 \mathrm{~s}$ and $t=6 \mathrm{~s}$ ).

At 11 second, the concrete at the base of three piers crushed and reinforcement was buckled, as shown in Figure 34 . The whole bridge collapsed at 12.5 seconds. 


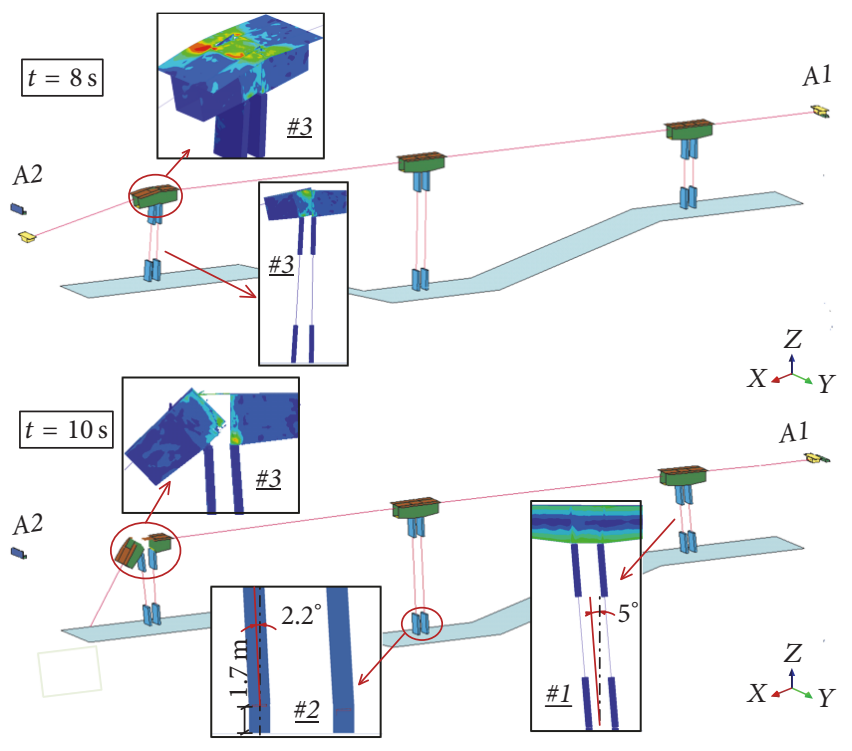

FIgURE 33: Collapse process of the bridge ( $t=8 \mathrm{~s}$ and $t=10 \mathrm{~s}$ ).
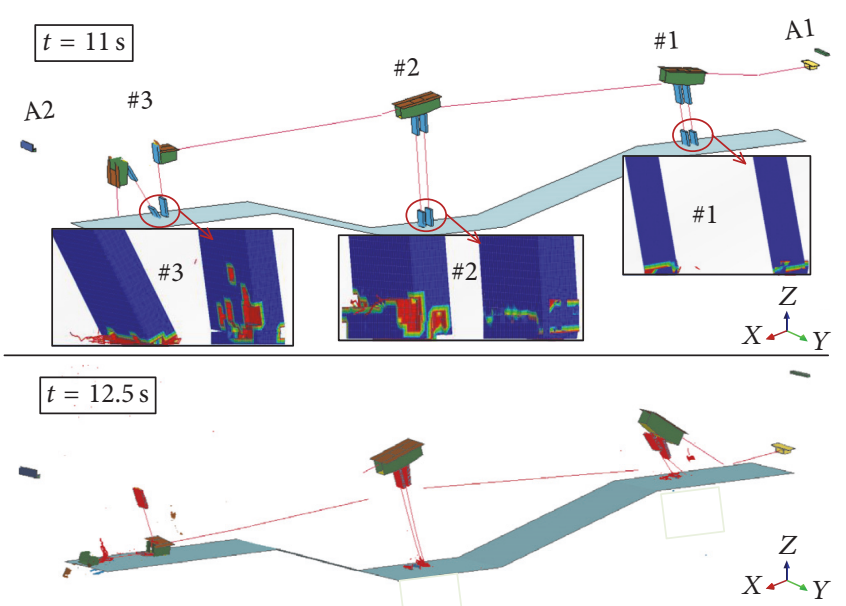

FIGURE 34: Collapse process of the bridge ( $t=11 \mathrm{~s}$ and $t=12.5 \mathrm{~s})$.

\section{Conclusions}

The following conclusions can be drawn from the numerical simulation:

(1) Based on the theory of multiscale FE modeling, the coupling method of rigid surface and displacement coordinate formulas were developed in this paper and reliability of coupling method was verified in both the component and structural levels. The numerical experiments show that the simplified multiscale FE model offers a good balance between efficiency and accuracy.

(2) The earthquake-induced collapse analysis of a multispan simply supported girder bridge was conducted using simplified multiscale FE modeling developed in this paper. The results show that the pounding forces at expansion joints are an important cause for collapse of this bridge. The energy dissipating dampers as restrainers for expansion joints are significantly effective in limiting the relative opening displacements at expansion joints of highway bridges.

(3) The seismic collapse analysis of a four-span RC continuous rigid frame bridge was conducted under bidirectional earthquake excitation based on simplified multiscale FE modeling approach. The results demonstrate that the simplified multiscale FE model developed in this paper can simulate the collapse process and local damage of complex bridge structures accurately and efficiently. Although the structural integrity of RC continuous rigid frame bridge is good, the main bridge structure will be instable and will collapse when the shortest bridge pier is invalid. It is important to conduct reasonable stiffness distribution for bridge piers with different heights in seismic design of RC continuous rigid frame bridges.

\section{Conflicts of Interest}

The authors declare that they have no conflicts of interest.

\section{Acknowledgments}

The authors gratefully acknowledge the support for this research by the National Natural Science Foundation of China under Grants no. 51578022 and no. 51678013 and the research project of Beijing Municipal Commission of Education under Grant no. KZ201610005013.

\section{References}

[1] H. Hao, K. Bi, N. Chouw, and W.-X. Ren, "State-of-theart review on seismic induced pounding response of bridge structures," Journal of Earthquake and Tsunami, vol. 7, no. 3, Article ID 1350019, 2013.

[2] H. Qiang, D. Xiuli, L. Jingbo, L. Zhongxian, L. Liyun, and Z. Jianfeng, "Seismic damage of highway bridges during the 2008 Wenchuan earthquake," Earthquake Engineering and Engineering Vibration, vol. 8, no. 2, pp. 263-273, 2009.

[3] Z. Xu, X. Lu, H. Guan, X. Lu, and A. Ren, "Progressive-collapse simulation and critical region identification of a stone arch bridge," Journal of Performance of Constructed Facilities, vol. 27, no. 1, pp. 43-52, 2013.

[4] W. Peng, R. Pan, and F. Dai, “Theoretic framework and finite element implementation on progressive collapse simulation of masonry arch bridge," Mathematical Problems in Engineering, vol. 2015, Article ID 707269, 2015.

[5] H. Jiang, J.-J. Wang, and S.-H. He, "Numerical simulation on continuous collapse of reinforced concrete girder bridge subjected to vessel collision," Zhendong yu Chongji, vol. 31, no. 10, pp. 68-73, 2012.

[6] K. Bi and H. Hao, "Numerical simulation of pounding damage to bridge structures under spatially varying ground motions," Engineering Structures, vol. 46, pp. 62-76, 2013.

[7] K. Bi, W.-X. Ren, P.-F. Cheng, and H. Hao, "Domino-type progressive collapse analysis of a multi-span simply-supported bridge: A case study," Engineering Structures, vol. 90, pp. 172182, 2015. 
[8] K. Bi and H. Hao, "Modelling of shear keys in bridge structures under seismic loads," Soil Dynamics and Earthquake Engineering, vol. 74, pp. 56-68, 2015.

[9] P. Ladeveze, A. Nouy, and O. Loiseau, "A multiscale computational approach for contact problems," Computer Methods Applied Mechanics and Engineering, vol. 191, no. 43, pp. 48694891, 2002.

[10] S. Bin and Z. Li, "Multi-scale modeling and trans-level simulation from material meso-damage to structural failure of reinforced concrete frame structures under seismic loading," Journal of Computational Science, vol. 12, pp. 38-50, 2016.

[11] M.-X. Tao and J.-G. Nie, "Multi-scale modeling for deformation mechanism analysis of composite joint substructures," Engineering Structures, vol. 118, pp. 55-73, 2016.

[12] F. Margiacchi, L. Salvatori, M. Orlando, M. De Stefano, and P. Spinelli, "Seismic response of masonry-infilled steel frames via multi-scale finite-element analyses," Bulletin of Earthquake Engineering, vol. 14, no. 12, pp. 3529-3546, 2016.

[13] R. W. McCune, C. G. Armstrong, and D. J. Robinson, "Mixeddimensional coupling in finite element models," International Journal for Numerical Methods in Engineering, vol. 49, no. 6, pp. 725-750, 2000.

[14] K. W. Shim, D. J. Monaghan, and C. G. Armstrong, "Mixed dimensional coupling in finite element stress analysis," Engineering with Computers, vol. 18, no. 3, pp. 241-252, 2002.

[15] Y. Ding, A. Li, D. Du, and T. Liu, "Multi-scale damage analysis for a steel box girder of a long-span cable-stayed bridge," Structure and Infrastructure Engineering, vol. 6, no. 6, pp. 725739, 2010.

[16] Z. X. Li, T. Q. Zhou, T. H. T. Chan, and Y. Yu, "Multi-scale numerical analysis on dynamic response and local damage in long-span bridges," Engineering Structures, vol. 29, no. 7, pp. 1507-1524, 2007.

[17] J.-G. Nie, M. Zhou, Y.-H. Wang, J.-S. Fan, and M.-X. Tao, "Cable anchorage system modeling methods for self-anchored suspension bridges with steel box girders," Journal of Bridge Engineering, vol. 19, no. 2, pp. 172-185, 2014.

[18] C.-J. Wang, "Failure study of a bridge subjected to pounding and sliding under severe ground motions," International Journal of Impact Engineering, vol. 34, no. 2, pp. 216-231, 2007.

[19] T. H. T. Chan, Z. X. Li, Y. Yu, and Z. H. Sun, "Concurrent multiscale modeling of civil infrastructures for analyses on structural deteriorating-Part II: Model updating and verification," Finite Elements in Analysis and Design, vol. 45, no. 11, pp. 795-805, 2009.

[20] Z. Li, Y. Chen, and Y. Shi, "Numerical failure analysis of a continuous reinforced concrete bridge under strong earthquakes using multi-scale models," Earthquake Engineering and Engineering Vibration, vol. 16, no. 2, pp. 397-413, 2017.

[21] T. J. Holmquist and G. R. Johnson, "A computational constitutive model for glass subjected to large strains, high strain rates and high pressures," Journal of Applied Mechanics, vol. 78, no. 5, Article ID 051003, 2011.

[22] H. Wang, Seismic failure modes and collapse analysis of $R C$ bridges based on multi-scale finite element modeling, Beijing University of Technology, 2016. 


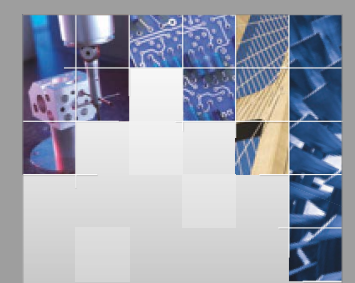

\section{Enfincering}
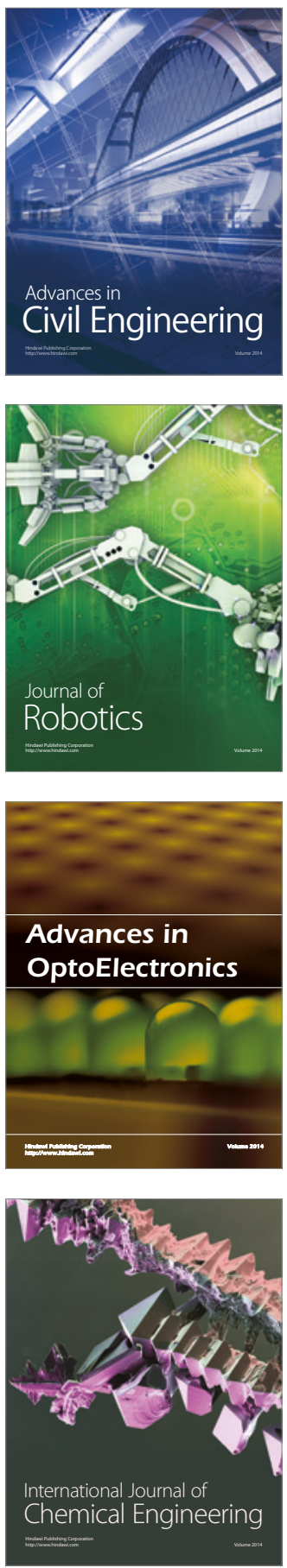

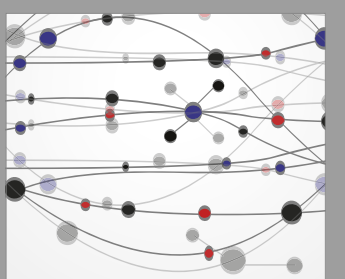

The Scientific World Journal

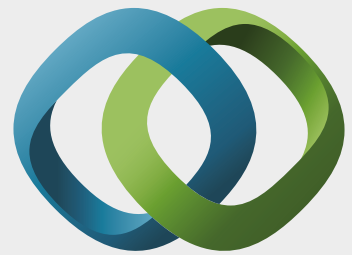

\section{Hindawi}

Submit your manuscripts at

https://www.hindawi.com
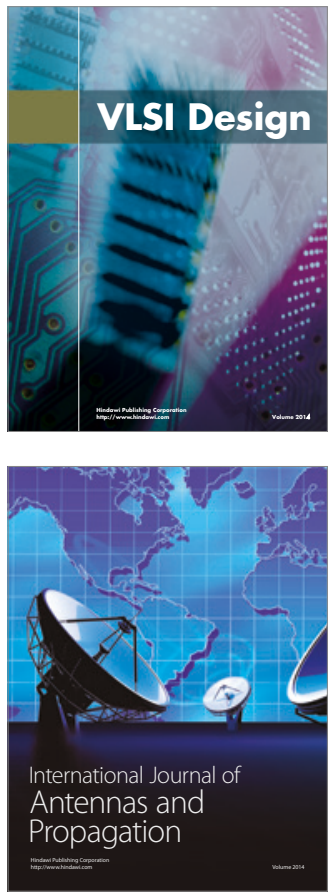

\section{Rotating}

Machinery
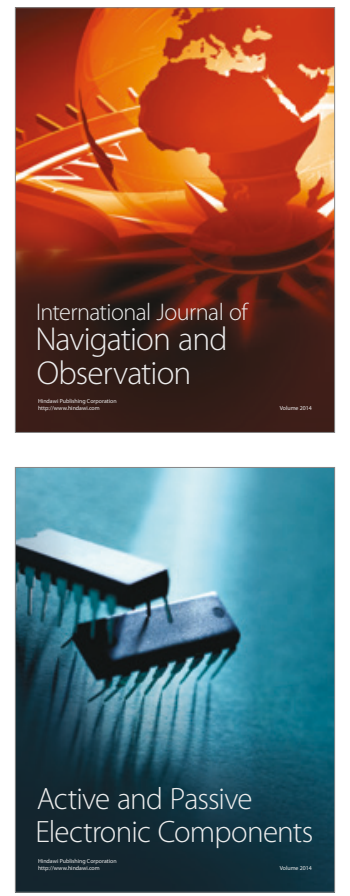
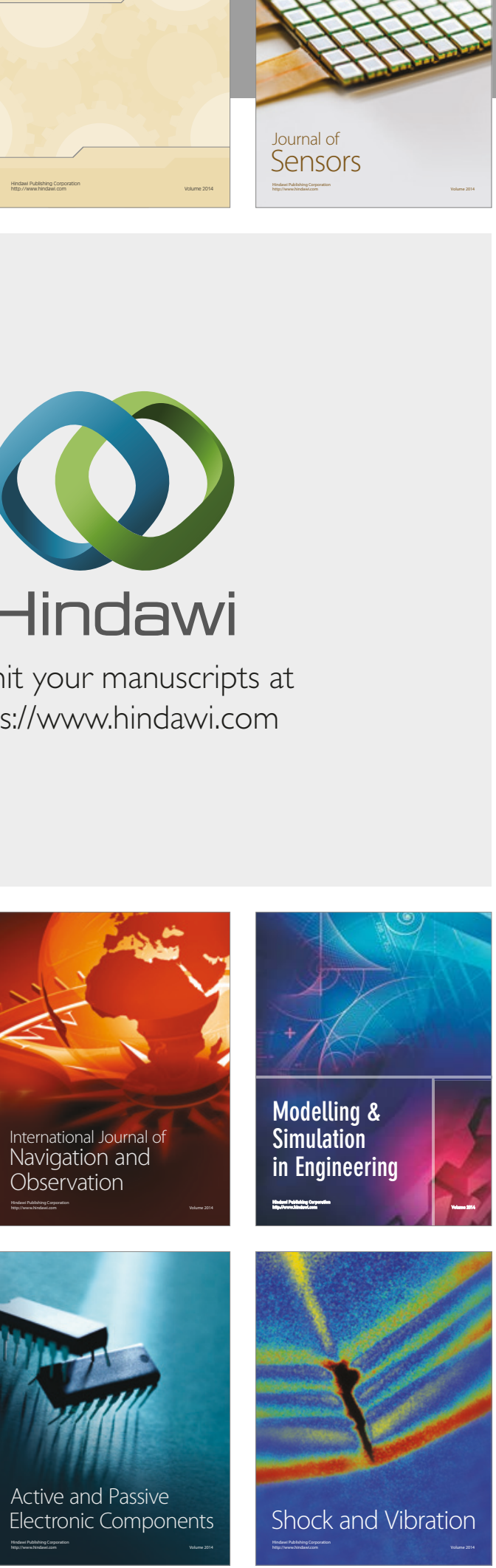
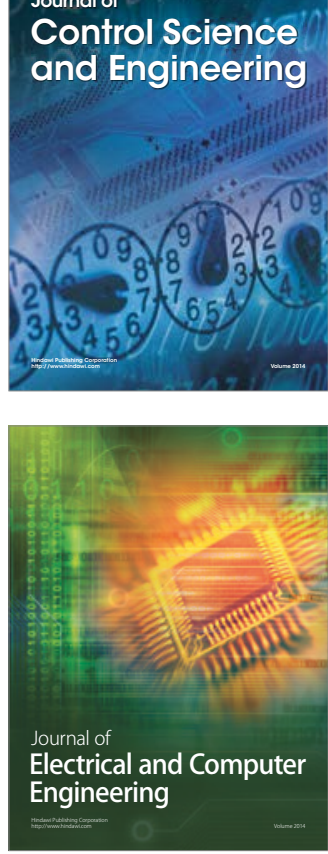

Distributed

Journal of

Control Science

and Engineering
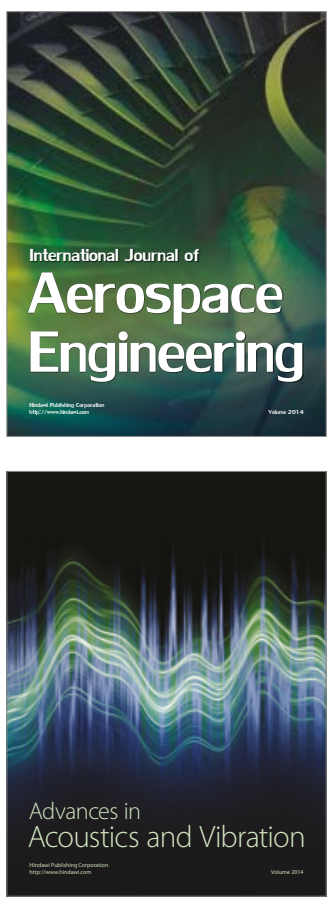

Sensor Networks 